\title{
DESIGN AND ANALYSIS OF SPROCKET FOR FORMULA STUDENT VEHICLE
}

\author{
E NIKHIL REDDY , K RAVI KUMAR , B CHANDRASHEKAR REDDY, \\ S VENKAT DILIP \\ Mr. B PRAVEEN KUMAR (ASSOCIATE PROFESSOR)
}

\author{
DEPARTMENT OF MECHANICAL ENGINEERING \\ GURU NANAK INSTITUTE OF TECHNOLOGY \\ (Affiliated to Jawaharlal Nehru Technological University) \\ Ibrahimpatnam, Ranga Reddy District - 501506
}

\begin{abstract}
In a Formula student vehicle, the sprocket is one of the important components in the chain drive which transmits power from the engine output shaft to the drive shaft. To ensure efficient power transmission, sprocket should be designed and manufactured properly. In this study the driven sprocket of the formula student vehicle has been designed in Solid works and analysed using FEA. ANSYS software has been used to perform Static analysis to calculate the stresses induced and deformations in the sprocket. And then the Fatigue analysis has been done to determine the Fatigue life and damage. The sprocket is then optimized for weight reduction and re-analysed in ANSYS for safety and reliability. Chain sprocket is one of the most important parts used in transmitting power from the engine to the drive shafts. This study mainly deals with the design and analysis of rear sprocket of a Formula Student car. This sprocket is designed such that it is light in weight and functions efficiently. The type of chain used is roller type chain. The main challenge faced is determining the proper material and number of teeth for chain sprocket. Many iterations were carried mathematically to determine the total number of teeth and final drive ratio. The CAD model was created in SolidWorks and Finite Element Analysis was carried out in ANSYS Static Structural module. Initially a solid sprocket was created without any slots for different materials and Static structural analysis was performed. For doing static analysis, the forces and torques acting on the teeth of sprocket were calculated. Boundary conditions were
\end{abstract}


applied such that the bolt ends were made to be fixed and parameters like tensile force, torque were applied at the sprocket teeth that were engaged during the operation. By observing the stress distribution in the solid sprocket, slots were created, in order to reduce the overall mass of the sprocket. Various CAD models were created in SolidWorks and were analyzed in ANSYS by applying static loads and assigning different materials. The best material and optimal design was selected based on the mass property and results obtained from ANSYS

KEYWORDS: Sprocket, Ansys, CAD, FEA

\section{INTRODUCTION}

\subsection{Sprocket}

A Sprocket or sprocket wheel is a profiled wheel with teeth, or cogs, that mesh with a chain, track or other perforated or indented material. The name sprocket applies generally to any wheel upon which radial projections engage a chain passing over it. Sprockets never meshed directly, and differs from a pulley. Sprockets have teeth and pulleys are smooth. Sprockets are used in bicycles, motorcycles, cars, tracked vehicles and other machinery either to transmit rotary motion between two shafts where gears are unsuitable or to impart linear motion to a track, tape etc. Perhaps the most common form of sprocket can found in the bicycle, in which the pedal shaft carries a large sprocket wheel which drives a chain, which in turn drives a small sprocket on the axle of the rear wheel. Two-wheelers are largely driven by sprocket and chain mechanism, a practice largely copied from bicycles. Sprockets are of various designs; a maximum of efficiency been claimed for each by its originator. Sprockets typically do not have a flange. Some sprockets used with timing belts, have flanges to keep the timing belt centred. Sprockets and chains are also used for power transmission from one shaft to another where slippage is not admissible. Sprocket chains being used instead of belts or ropes and sprocket wheels instead of pulleys. They can run at high speed and some form of chains constructed to be noiseless even at high speed.

\subsection{Selection of material:}

The selection of material which is used to manufacture the sprocket depend on the strength and service conditions like wear and noise etc. It involves the cost as well as material performance required. The sprockets are manufactured from Metallic or Non-Metallic materials. The steel is widely used for the manufacturing of Sprocket due to it's wear resistant properties, excellent machinability, and the ease of producing complicated shapes by manufacturing. 


\subsection{Importance of Sprocket:}

Chain and sprockets are some of the most important parts of a motorcycle drivetrain and their maintenance is a crucial part of safe riding. These are used for a very critical task of delivering power from the gearbox to the rear wheel. A faulty chain set can make your motorcycle cripple or sometimes the situation can become even dangerous. That means we need to take special care about this part and for that, we should know about the chain maintenance.

\subsection{Types of Sprocket:}

1. Double pitch sprocket

2. Multiple strand sprocket

3. Quick Disconnect sprocket

4. Taper-Lock sprocket

5. Steel Slip sprocket

6. Double Single Sprocket

7. Idler Sprocket

8. Double plus Sprocket

\section{Double pitch Sprocket:}

These are similar to standard sprockets, but the number of teeth is half when compared to standard one. These are used with small roller and double pitch chain to accommodate longer distances between rollers. Common chain sizes are 2040, 2050, 2060, 2080, 2100, 2042, 2052, 2062, 2082, and 2102 for larger diameters.

\section{Multiple strand sprocket:}

Multi-strand sprockets are used where higher torque and power are needed, or where two or more items are being powered by a common drive shaft. Available in 40 to 160-chain pitch with plain, finished, taper-lock, or QD style hubs.

\section{Quick Disconnect sprocket:}

QD sprockets are used where higher working loads and high clamp loading on the shaft is desirable. They are flanged and use anchor bolts around the circumference. Sprockets with tapered bushings are easy to install and remove, provide clamp force, and align the sprocket 4. Taper-Lock sprocket:

Taper-lock sprockets utilize a split through the taper and flange to provide a true clamp on the shaft. A taperlock bushing is retained to the sprocket with set screws. They offer flexibility by allowing multiple sized bores for a single bushing size.

\section{Steel Slip sprocket:}


Steel split sprockets are split through the entire radius for easy installation and removal. The halves are held together by bolts. This style is available in pitch sizes 40 to 240, and bore diameters of 3/4 through 6 in.

\section{Double Single Sprocket:}

Double single sprockets are used in applications where two or more items are powered by a common drive shaft. The space between the plates is wider than a multi-strand sprocket and allows two separate strands of chain to engage without contacting the other. One strand may exit in a different direction than the other.

\section{Idler Sprocket:}

Idler sprockets used where the chain may experience slack due to long lengths, where there is a non-adjustable drive shaft, or where the chain guided around an obstruction. Using idler sprockets prevents chain whipping and uneven load distribution.

\section{Double plus Sprocket:}

Double plus sprockets are specifically designed to be used with the Double Plus chain and are in conveyor applications where a product is moving at twice the speed of the drive system powering the conveyor. Benefits include less noise and longer chain life.

There are a few constraints that apply to all aspects of designing a drivetrain of a formula- style car and these are discussed in detail in the majority of the following sections in such a way that the complete sprockets are designed in correspondence to the FORMULA BHARAT rulebook. 


\section{LITERATURE REVIEW}

This section lists literature sources that were reviewed and found to be satisfactory in their content.

Different design optimization processes and techniques by different researchers. Some of them re-designed the chain sprocket, analysis using FEA and using the results from FEA, they optimized the weight of sprocket. Most researchers have used different grades of steel as their base material and re-designed the sprocket by using different CAD software, and Solid works. Few have used composite materials like Carbon Fibre or Nylon66GF30 also as an alternative to steel and compared to earlier research. Some have given heat treatment and other types of chemical treatment to the sprocket to enhance its mechanical properties. For this review, many international and national papers were helpful. Worldwide researchers have applied their efforts to design and tried to optimize chain sprocket. We took some of the reviews on sprocket from different researchers as the following explanations below.

\section{"Diagnosis for the Failure of Sprockets and Chain Drive" (Tushar and Y. A Kharche S.}

Hingve )

In this study, they found the faults by using the various faults detection techniques and analysed them. They tried to diagnose the faults by using techniques. They found out the major breakdowns in mechanisms due to sprockets failure causing production losses to the company and suggested countermeasures by which these problems are reduced. The identified the root causes of breakdowns using cause and found in the sprocket and chain can be maintained, by considering the design parameter chain effect diagram. Finally, they studied the diagnosis of the faults for eliminating causes. By using, the Design of chain sprocket for the particular cause it would help to reduce the defects like wear in sprockets, reduction of noise in the drive by using the proper chain for the alignments and vibrations in the sprockets using modal analysis, 26 tooth were preferred according to the polygonal action climbing on the sprocket can be eliminated.

“Design and Analysis of carbon fibre Sprocket" (Nikhil P. Ambole \& Prof. P. R. Kale)

In this research, carbon fibre was introduced as a replacement for conventional mild steel. They have done CAD through reverse engineering and analysis was carried out using Hyper-mesh and ANSYS. Finite element analysis was then carried out by using Mild Steel (IS 2062) and Carbon fibre. To validate the FEA analysis with the Experimental analysis, both steel and carbon fibre sprockets tested on UTM for experimental results. From the results of the finite element analysis, they observed that stresses Review on Design Optimization of Sprocket Wheel Using Different Techniques 59 are maximum at joint locations. It also observed that both the materials have stress values less than their respective permissible yield stress values. Hence, their design was 
safe. From analysis results and comparison of properties of all the materials, they found that carbon fiber was the material, which was having the least density, and it was easily available and cheap as compared to other alternate materials. Also, the machining cost for carbon fiber was less. Hence, it was the best-suited alternate material for sprocket and expected to perform better with a satisfying amount of weight reduction.

Pauschitz et al in 2008, in their research work, gave an outline of the status in future trends of wear at elevated temperature of selected metallic materials. This study may be useful for stainless steel chain performance improvement at higher temperatures.

Design Optimization of Chain Sprocket Using Finite Element Analysis”, In this research, the chain sprocket was designed and analysed using Finite Element Analysis for safety and reliability. ANSYS software was used for static and fatigue analysis of sprocket design. Using these results optimization of sprocket for weight reduction have been done. As sprocket undergo vibration, modal analysis was also performed. The design of sprocket has been successfully optimized with weight reduction of $15.67 \%$. Also von-mises stress of modified design was lesser than preliminary design with little increase in deformation, which ultimately results in the safety and reliability of design.

"Design Optimization of Chain Sprocket Using Finite Element Analysis" (Parag Nikam and Rahul Tanpure)

The load distributions on sprocket tooth and chain strands were studied with the help of a model and experimental analysis. The authors reported that the load distribution was not same on each tooth and varied with pressure angle and number of teeth. The authors also made a study on the effect of lubrication, misalignment, sprocket rotation at low speeds on load dynamics.

\section{"Experimental load distributions for double pinch steel roller chains on steel sprockets" (Eldiwany \& Marshek)}

Considering all the different reviews, in this project we have designed a sprocket that will sustain the applied loads at different stages of analysis in design process.

\section{PROBLEM STATEMENT}


The sliding motion between chain roller and sprocket tooth causes friction wear and wear occur in pin hole of chain rollers making the chain to elongate and so that chain becomes slack. Chain sprocket has problems like breaking of bushings and/or rollers, breaking of plates and pins (unusual cracks), quickly wear of sprockets, Worn rollers, etc. Possible causes of these problems are significant overload breakage, high impact pressure, combination of worn chain with new sprockets, excessive chain wear far beyond replacement level etc. Also, there is a wear on sprocket tooth and outer surface becomes rough affecting the transmission of motion in motorcycle. According to survey after approx. $20000 \mathrm{~km}$ of motorcycle drive chain sprocket assembly needs to be replaced 4.METHODOLOGY

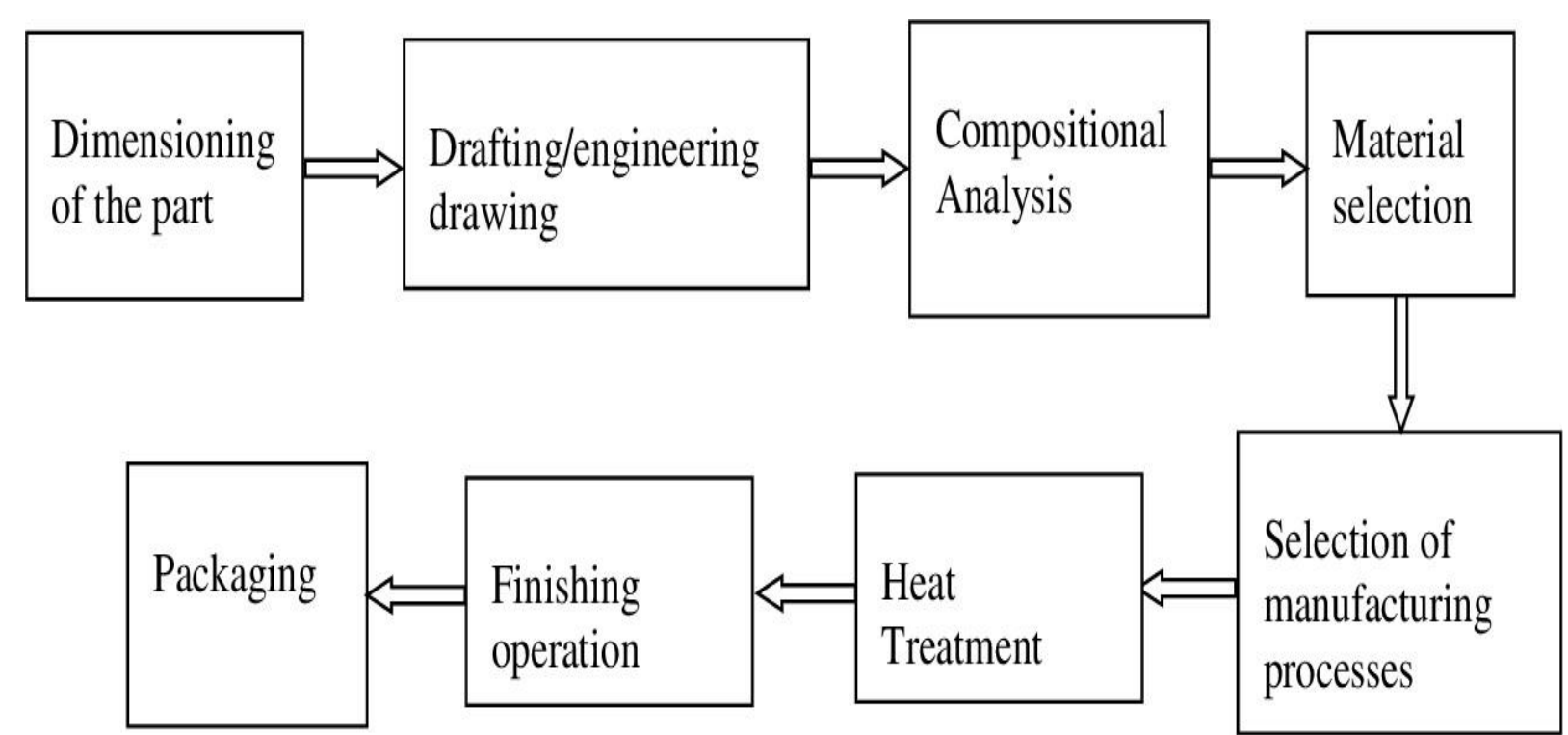

To manufacture sprocket, we have several methods to do this for Formula Student Vehicle. Various methods in manufacturing of sprocket:

1. CNC Method

2. Pressing Method

3. Water Jet Cutting Method

4. Crio Jet Method

5. Laser Cutting Method

6. Plasma Cutting Method 
7. Electrical Discharging Machining

8. Casting and Machining

As shown above, we have various methods in manufacturing of sprocket, from those we have selected water jet cutting method for the Formula Student Vehicle because of the following specifications.

\subsection{FORGING}

Forging is a manufacturing process involving the shaping of metal using localized compressive forces. The blows are delivered with a hammer or a die. Forging is often classified according to the temperature at which it is performed cold forging, warm forging, or hot forging etc. We have chosen to go with impression-die forging process. Forging process does not change the material properties compared to other manufacturing processes

For Machining of the forged component, we have decided to go with Water jet cutting because of the following reasons which are discussed in detail.

\subsection{WATER JET CUTTING METHOD:}

\section{Working principle:}

All waterjets follow the same principle of using high-pressure water focused into a beam by a nozzle. Most machines accomplish this by first running the water through a high- pressure pump. There are two types of pumps used to create this high pressure; an intensifier pump and a direct drive or crankshaft pump. A direct-drive pump works much like a car engine, forcing water through high-pressure tubing using plungers attached to a crankshaft. An intensifier pump creates pressure by using hydraulic oil to move a piston forcing the water through a tiny hole. The water then travels along with the high-pressure tubing to the nozzle of the waterjet. In the nozzle, the water is focused into a thin beam by a jewel orifice. This beam of water ejected from the nozzle, cutting through the material by spraying it with the jet of speed about Mach 3, around 2,500 ft. /s (760 m/s). The process is the same for abrasive waterjets until the water reaches the nozzle. Here abrasives such as garnet and aluminium oxide fed into the nozzle via an abrasive inlet. The abrasive then mixes with the water in a mixing tube and forced out the end at high pressure.

\subsection{Advantages of Water Jet Cutting:}

1. An important advantage of the water jet is the ability to cut material without interfering with its inherent structure, as there is no heat-affected zone (HAZ). 
2.Minimizing the effects of heat allows metals to cut without harming or changing intrinsic properties. Sharp corners, bevels, pierce holes, and shapes with minimal inner radii are all possible.

3. Water jet cutters are also capable of producing intricate cuts in material. With specialized software and 3-D machining heads, complex shapes produced.

The kerf, or width, of the cut adjusted by swapping parts in the nozzle, as well as changing the type and size of abrasive. Typical abrasive cuts have a kerf in the range of 0.04 to 0.05 in $(1.0-1.3 \mathrm{~mm})$, but can be as narrow as 0.02 inches $(0.51 \mathrm{~mm})$. Non-abrasive cuts are normally 0.007 to 0.013 in $(0.18-0.33$ 
4. $\mathrm{mm})$, but can be as small as 0.003 inches $(0.076 \mathrm{~mm})$, which is approximately that of a human hair. These small jets can permit small details in a wide range of applications.

5. Water jets can attain accuracy down to 0.005 inches $(0.13 \mathrm{~mm})$ and repeatability down to 0.001 inches $(0.025 \mathrm{~mm})$.

6. Cuts almost any material - When compared to other cutters, the waterjet cutter can handle just about any material or product that a traditional cutter can. Traditional tough materials such as bullet proof glass, stone, metals or even materials with reflective or uneven surfaces cut through with waterjet.

7. Metal cutting using water jet technology eliminates the risk of cross contamination since there is no contact medium.

\subsection{Dis-advantages of Water Jet Cutting:}

1. Cutting Time - While the waterjet cutter can cut most of the same materials, very often the cutting takes longer than a traditional cutter. More time cutting means less output.

2. Orifice Failure - Low-quality waterjet orifices down and disrupt cutting, resulting in lost time and productivity.

3. Greater Thickness, Less Accuracy - The thicker a material the further the stream is away from the nozzle at its point of impact. A less consistent impact of waterjet changes the cutting accuracy from top to bottom. Often, the jet can spread and make more of a diagonal cut than a straight up and down cut.

4. Starting Costs - In the beginning, finding and implementing the additional abrasive materials, like granite, to increase the efficiency of the cutter can be very expensive compared to a simple plasma cutter.

\subsection{Availability of Water Jet Cutting machines:}

Commercial water jet cutting systems are available from manufacturers all over the world, in a range of sizes, and with water pumps capable of a range of pressures. Typical water jet cutting machines have a working envelope as small as a few square feet, or up to hundreds of square feet. Ultra-high-pressure water pumps are available from as low as 40,000 psi (280 MPa) up to 100,000 psi (690 MPa).

\subsection{Process Characteristics of Water Jet Cutting:}

There are six main process characteristics of water jet cutting:

1. Uses a high-velocity stream of Ultra High-Pressure Water 30,000-90,000 psi (210-620 MPa) which produced by a high-pressure pump with possible abrasive particles suspended in the stream.

2. It used for machining a large array of materials, including heat-sensitive, delicate or very hard materials.

3. Produces no heat damage to the workpiece surface or edges.

4. Nozzles are typically made of sintered boride or composite tungsten carbide. 
5. Produces a taper of less than 1 degree on most cuts, which can be reduced or eliminated by slowing down the cut process or tilting the jet.

6. The distance of the nozzle from the workpiece affects the size of the kerf and the removal rate of the material. The typical distance is .125 in $(3.2 \mathrm{~mm})$. Temperature is not as much of a factor.

\subsection{Cost of Water Jet Cutting:}

Water jet cutting machines are more expensive to purchase, operate and maintain. The typical price range for a waterjet with a single cutting head is approximately USD \$100- \$135 per hour, though high-end parts can run up to $\$ 2,000$ per hour depending on material type and thickness as well as part geometry. 


\section{DESIGN OF SPROCKET FOR FORMULA STUDENT VEHICLE}

\subsection{Introduction:}

This report is made as a pre-design and analysis report of a student racing car designed for motorsport competition organized by Formula Bharath. For better performance of race cars, it should be made sure that the designing of the component and analysis of those components is done in the right way.

As it is difficult to produce or manufacture and test each and every component, here we use CAD software like SolidWorks, Catia, Creo for designing components. These components are further subjected to mechanical forces and are virtually analyzed for fatigue life, deformation, stresses developed. This procedure helps in reducing manufacturing costs and time significantly.

\subsection{Engine Specifications:}

As per the standard rules of formula Bharath, the engine used to power the car should be a 4-stroke engine with displacement less than 710cc. As there are multiple options available in the market like KTM 390, CBR 600R, GSXR 600, RE 500e, etc., Depending on the power required and ease of availability, KTM 390 is found to be a more suitable engine for the formula student vehicle.

The specifications of the KTM 390 are provided in the following table.

\begin{tabular}{|l|l|}
\hline Engine Description & 1 -cylinder 4 stroke engine \\
\hline Displacement & $373.2 \mathrm{cc}$ \\
\hline Maximum Power & $43.5 \mathrm{PS} @ 9000 \mathrm{rpm}$ \\
\hline Maximum Torque & $35.3 \mathrm{~N}-\mathrm{m} @ 7000 \mathrm{rpm}$ \\
\hline No. of Cylinder & 1 \\
\hline Cooling System & Liquid Cooled \\
\hline Bore & $89 \mathrm{~mm}$ \\
\hline Stroke & $60 \mathrm{~mm}$ \\
\hline Compression Ratio & $12.8: 1$ \\
\hline No. of gears & 6 \\
\hline Primary Gear Ratio & $30: 80$ \\
\hline Secondary Gear Ratio & $15: 45$ \\
\hline Fuel Injection System & Bosch Closed Loop type \\
\hline
\end{tabular}

Table No-1: Specifications of KTM 390 
As the KTM 390 engine is used, the majority of the gear ratios are pre-designed by the company. The only option available to achieve the required torque and speed is by manipulating the Secondary gear reduction.

In order to deliver the required torque and speed the secondary drive ratio found out to be $3.46: 1$ and the primary drive ratio is $2.66: 1$.

Overall gear ratio $=$ primary gear ratio*Secondary gear ratio*Individual gear ratio Here the individual gear ratios of stock engine are given below:

\begin{tabular}{|c|c|}
\hline GEAR & INDIVIDUAL GEAR RATIO \\
\hline $1_{\mathrm{st}}$ & 2.6666 \\
\hline $2^{\text {nd }}$ & 1.8571 \\
\hline $3_{\mathrm{rd}}$ & 1.4211 \\
\hline $4_{\text {th }}$ & 1.1428 \\
\hline $5_{\text {th }}$ & 0.9565 \\
\hline 6 th & 0.8400 \\
\hline
\end{tabular}

Table No-2: Individual gear ratio

The individual gear ratios are found out by opening the gearbox of stock KTM 390 engine and manually counting the number of teeth on each gear and dividing them by the number of teeth on their respective countershaft gears. Overall gear ratio at $1^{\text {st }}$ gear $=2.6666 * 3 * 2.66$

$$
=21.2794
$$

Similarly, Overall gear ratios are found out to be:

\begin{tabular}{|c|c|}
\hline GEAR & OVERALL GEAR RATIOS \\
\hline $1_{\text {st }}$ & 21.2794 \\
\hline 2nd & 14.8196 \\
\hline 3rd & 11.3403 \\
\hline 4 th & 9.11954 \\
\hline 5 th & 7.63287 \\
\hline 6 th & 6.7032 \\
\hline
\end{tabular}

Table No-3: Overall gear ratio

\subsection{Torque Calculations:}


The torque value at each individual gear is obtained by the Formula.

Torque at each gear $=$ Maximum engine torque $*$ Overall gear ratio of that gear

\{ Maximum engine torque $=35.3 \mathrm{~N}-\mathrm{m} @ 7000 \mathrm{rpm}$ as the given in the engine specifications \}.

Torque at $1^{\text {st }}$ gear $=35.3 * 21.2794$

$=751.1652 \mathrm{~N}-\mathrm{m}$

Similarly torque at each gear can be calculated. The below table shows the values of torque at each gear.

\begin{tabular}{|c|c|}
\hline GEAR & TORQUE AT EACH GEAR \\
\hline $1_{\text {st }}$ & $751.1652 \mathrm{~N}-\mathrm{m}$ \\
\hline 2nd & $523.1339 \mathrm{~N}-\mathrm{m}$ \\
\hline 3rd & $400.3153 \mathrm{~N}-\mathrm{m}$ \\
\hline $4_{\text {th }}$ & $321.9199 \mathrm{~N}-\mathrm{m}$ \\
\hline 5 th & $269.4403 \mathrm{~N}-\mathrm{m}$ \\
\hline 6th & $236.6229 \mathrm{~N}-\mathrm{m}$ \\
\hline
\end{tabular}

Table No-4: Torque Calculations

\subsection{RPM Calculations:}

$\mathrm{RPM}$ at $1^{\text {st }}$ gear $=$ Engine $\mathrm{RPM} /$ Gear ratio at $1^{\text {st }}$ gear

$=7000 / .21 .2794$

$=328.9566$

Similarly, RPM at each gear can be calculated. The below table shows the calculated values of RPM at each gear.

\begin{tabular}{|c|c|c|}
\hline GEAR & RPM & RPS \\
\hline 1st & 328.9566 & 5.4825 \\
\hline 2nd & 472.3455 & 7.8724 \\
\hline 3rd & 617.2633 & 10.2877 \\
\hline 4th & 767.5822 & 12.7930 \\
\hline 5th & 917.0862 & 15.2847 \\
\hline 6th & 1044.2773 & 17.4046 \\
\hline
\end{tabular}

Table No-5: RPM Calculations

The diameter of the wheel $=21.2$ inches

The radius of the wheel $=10.60$ inches $=0.26924 \mathrm{~m}$

\subsection{Traction Force Calculation:}


Traction Force $=$ Torque at each gear/Radius of the wheel at $1^{\text {st }}$ gear, $751.1652 / 0.26924=3217.7354 \mathrm{~N}$.

Similarly, traction force at every gear is calculated. The below table shows the calculated values.

\begin{tabular}{|c|c|}
\hline GEARS & TRACTION FORCE \\
\hline $1_{\text {st }}$ & $2989.9465 \mathrm{~N}$ \\
\hline $2_{\text {nd }}$ & $1943.1184 \mathrm{~N}$ \\
\hline $3_{\text {rd }}$ & $1486.8344 \mathrm{~N}$ \\
\hline $4_{\text {th }}$ & $1195.6614 \mathrm{~N}$ \\
\hline 5 th & $1000.7439 \mathrm{~N}$ \\
\hline 6 th & $878.5849 \mathrm{~N}$ \\
\hline
\end{tabular}

Table No-6: Traction Force Calculations

Force required to overcome the rolling resistance and aerodynamics.

Force total $=$ Rolling resistance + Aerodynamic resistance

Rolling resistance, $\mathrm{f}_{\mathrm{r}}=\mathrm{f}^{*} \mathrm{mg} \mathrm{F}=\mathrm{Co}$-efficient of

rolling resistance $\mathrm{g}=9.81 \mathrm{~m} / \mathrm{s}^{2}$

Mass of vehicle $=320 \mathrm{~kg} \mathrm{f}=$

$0.0149 * 320 * 9.81=43.9488 \mathrm{~N}$

Aerodynamic drag $=0.5 \int \mathrm{Cd} A(\mathrm{v}+\mathrm{Vn})^{2}$

$=458.27 \mathrm{~N}$

$\mathrm{F}_{\text {total }}=458.27+43.9488$

$=502.2188 \mathrm{~N}$.

\subsection{Acceleration and Speed Calculations:}

Therefore, the available force at the wheels is given by

Available force $=$ Total traction force - Total resistance force

Acceleration at each gear $=$ force available/weight at $1^{\text {st }}$ gear $=$

$2713.3669 / 320=8.4792 \mathrm{~m} / \mathrm{s}^{2}$

Similarly, acceleration values at each gear are calculated. The table below shows the values of acceleration at each gear. 


\begin{tabular}{|c|c|c|}
\hline Gear & Available Force (N) & Acceleration $\left(\mathbf{m} / \mathbf{s}^{\mathbf{2}}\right)$ \\
\hline 1st $^{\text {st }}$ & 2713.3669 & 8.4792 \\
\hline 2nd & 1737.5352 & 5.4292 \\
\hline 3rd & 1211.4453 & 3.7857 \\
\hline 4th & 875.8426 & 2.7370 \\
\hline 5th & 651.1955 & 2.0349 \\
\hline 6th & 507.7073 & 1.58 \\
\hline
\end{tabular}

Table No-7: Acceleration and Speed Calculations

SPEED AT EACH GEAR $=$ RPS $* 2 \pi r * 3.6$

At $1^{\text {st }}$ gear,

\section{$5.4825 * 2 \pi * 0.26924 * 3.6=33.3887 \mathrm{KMPH}$}

Similarly, speed at each individual gear is calculated. The below table specifies the speed at every gear.

\begin{tabular}{|c|c|c|}
\hline GEAR & SPEED (KMPH) & ENGINE RPM \\
\hline $1 \mathrm{sT}$ & 33.3887 & 7000 \\
\hline $2 \mathrm{ND}$ & 47.9433 & 7000 \\
\hline $3 \mathrm{RD}$ & 62.6527 & 7000 \\
\hline $4 \mathrm{TH}$ & 77.9101 & 7000 \\
\hline $5 \mathrm{TH}$ & 93.0847 & 7000 \\
\hline 6TH & 105.9950 & \\
\hline
\end{tabular}

Table No-8: Speed at each Gear

By observing the above results, we came to the conclusion that the secondary drive ratio which is taken as 3.46:1, is the required Reduction gear ratio to achieve our design speed and torque values.

As the stock engine's output gear has 15 teeth, the number of teeth required on the driven sprocket is found out to be 52 . $(\mathrm{X}: 15=3.46: 1)$ 


\subsection{Designing of Sprocket:}

The stock engine output gear has a pitch of0.625-inch meshing with a chain of chain number \#520. The specifications of the \#520 chain are listed below.

Chain \#520

\begin{tabular}{|l|l|}
\hline Chain number & 520 \\
\hline Pitch & $518 "$ \\
\hline Roller Diameter & $0.400 "$ \\
\hline Roller Width & $114 "$ \\
\hline
\end{tabular}

Table No-9: Standard Dimensions of Chain

The driven Sprocket with 52 teeth is designed on the basis of chain number \# 520 pitch and the below diagram is given as an idea of the tooth geometry.

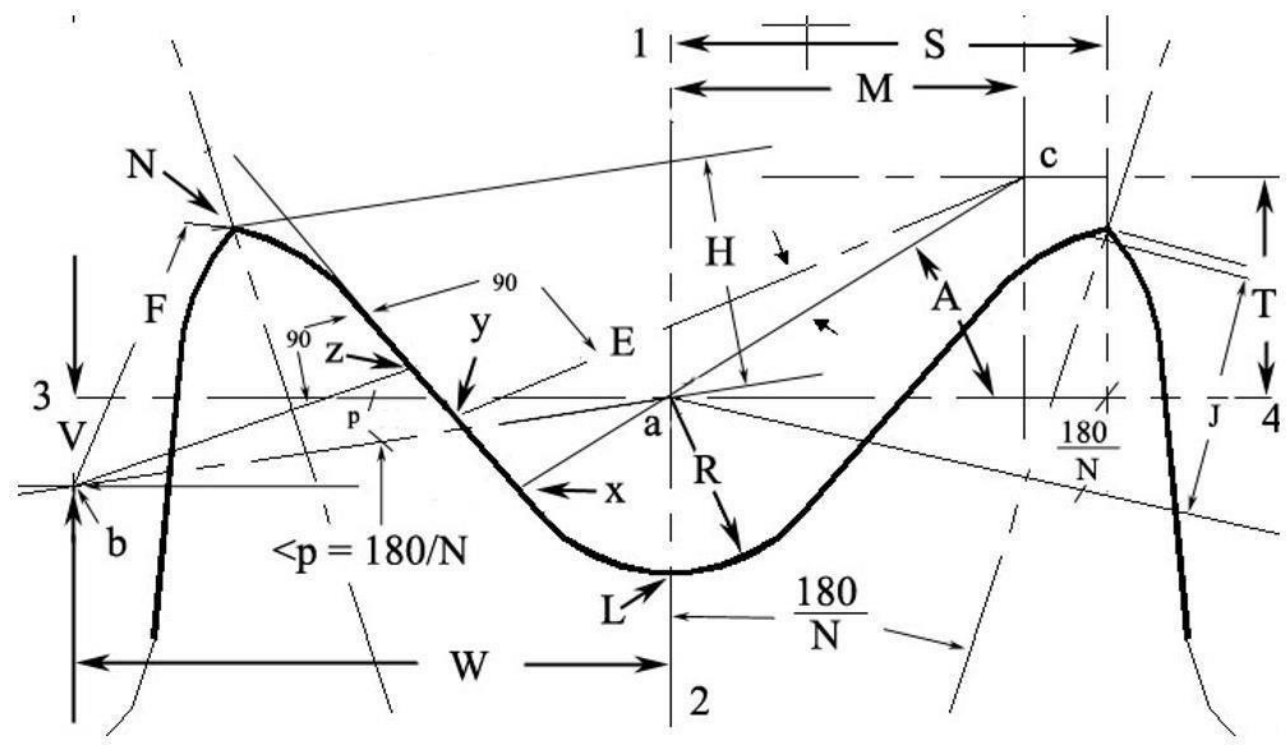

Figure No: 1.0 Tooth Geometry

The tooth geometry of the sprocket is the geometric path followed by the chain roller as it moves over the teeth of the sprocket. This shape of the tooth is related to the chain pitch, seating curve radius, and topping curve. The geometry or tooth curve design also includes the clearance required for the smooth engagement of the chain roller and sprocket teeth. 
The following formulae are used for the generation of tooth geometry are derived from the American chain association- chain for power transmission and material handling handbook representing the industry standards

\begin{tabular}{|l|l|}
\hline Ds $=($ Seating curve diameter $)=1.0005$ & $\mathrm{xy}=\left(2.605 \mathrm{D}_{\mathrm{r}}+0.003\right) * \sin \left(9^{\circ}-28^{\circ} / \mathrm{N}\right)$ \\
$\mathrm{Dr}+0.003$ & \\
\hline $\mathrm{R}=\mathrm{Ds} / 2=0.5025 \mathrm{Dr}+0.0015$ & $\begin{array}{l}\mathrm{Yz}=\mathrm{D}_{\mathrm{r}}\left[1.4 \sin \left(17^{\circ}-64^{\circ} / \mathrm{N}\right)-0.8\right. \\
\sin \left(18^{\circ}-\right.\end{array}$ \\
& $\left.\left.56^{\circ} / \mathrm{N}\right)\right]$ \\
\hline $\mathrm{A}=35^{\circ}+60^{\circ} / \mathrm{N}$ & $\mathrm{ab}=1.4 \mathrm{D}_{\mathrm{r}}$ \\
\hline $\mathrm{B}=18^{\circ}-56^{\circ} / \mathrm{N}$ & $\mathrm{V}=1.4 \mathrm{D}_{\mathrm{r}} \sin 180^{\circ} / \mathrm{N}$ \\
\hline $\mathrm{ac}=0.8^{*} \mathrm{Dr}$ & $\mathrm{W}=1.4 \mathrm{D}_{\mathrm{r}} \cos 180^{\circ} / \mathrm{N}$ \\
\hline $\mathrm{M}=0.8^{*} \mathrm{D}_{\mathrm{r}} \cos \left(35^{\circ}+60^{\circ} / \mathrm{N}\right)$ & $\mathrm{H}=\sqrt{\mathrm{F}^{2}-\left(1.4 \mathrm{D}_{\mathrm{r}}-\mathrm{P} / 2\right)^{2}}$ \\
\hline $\mathrm{T}=0.8^{*} \mathrm{D}_{\mathrm{r}} \sin \left(35^{\circ}+60^{\circ} / \mathrm{N}\right)$ & $\mathrm{S}=\mathrm{P} / 2 \cos 180^{\circ} / \mathrm{N}+\mathrm{H} \sin 180^{\circ} / \mathrm{N}$ \\
\hline $\mathrm{E}=1.3025 \mathrm{D}_{\mathrm{r}}+0.0015$ & $\mathrm{PD}=\mathrm{P} / \sin \left(180^{\circ} / \mathrm{N}\right)$ \\
\hline $\mathrm{F}=\operatorname{Dr}\left[0.8 \cos \left(18^{\circ}-59^{\circ} / \mathrm{N}\right)+1.4 \cos \left(17^{\circ}-64^{\circ} / \mathrm{N}\right)-1.3025\right]-0.0015$ \\
\hline
\end{tabular}

Table No-10: Formulae for designing

Where,

Ds = seating curve diameter

$\mathrm{Dr}=$ roller diameter

$\mathrm{PD}=$ pitch circle diameter

$\mathrm{N}=$ number of teeth

$\mathrm{P}=$ pitch

\subsection{Procedure for designing a Sprocket:}

1.Determine all the above values by substituting the known values in the formulae mentioned in the preceding table. Enter the data in the table below.

\begin{tabular}{|l|c|}
\hline $\mathrm{Ds}=0.405$ & $\mathrm{Xy}=0.15376$ \\
\hline $\mathrm{R}=0.2025$ & $\mathrm{Yz}=0.05903$ \\
\hline $\mathrm{A}=36.1538$ & $\mathrm{Ab}=0.56$ \\
\hline $\mathrm{B}=16.9230$ & $\mathrm{~V}=0.3381$ \\
\hline
\end{tabular}




\begin{tabular}{|l|l|}
\hline $\mathrm{Ou}=0.32$ & $\mathrm{~W}=0.5589$ \\
\hline $\mathrm{M}=0.2583$ & $\mathrm{H}=0.2106$ \\
\hline $\mathrm{T}=0.1887$ & $\mathrm{~S}=0.3246$ \\
\hline $\mathrm{E}=0.225$ & $\mathrm{Pd}=10.3513$ \\
\hline $\mathrm{F}=6.32256$ & \\
\hline
\end{tabular}

Table No-11: Calculation table

2. Draw the pitch circle with a radius of $1 / 2 \mathrm{PD}$.

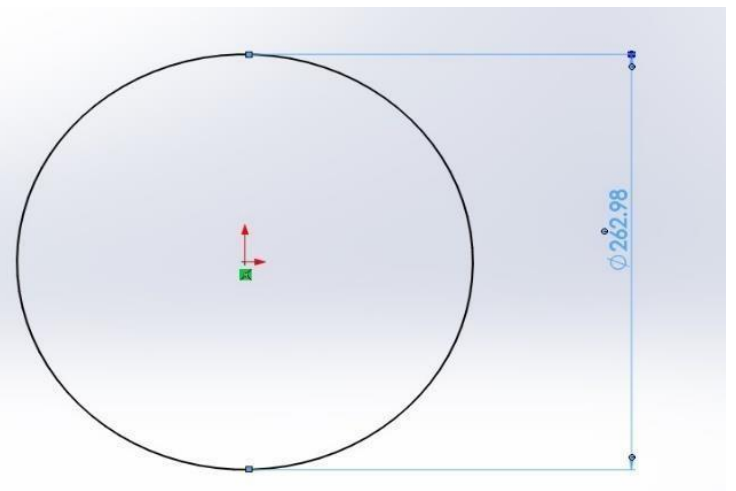

Figure No:1.1 Pitch Circle

3. Draw a vertical construction line $(1,2)$ passing through the center of pitch circle and also a horizontal line $(3,4)$ as a tangent to the pitch circle as shown in the figure. Mark the point of intersection of the lines $(1,2)$ and $(3,4)$ as point a. 


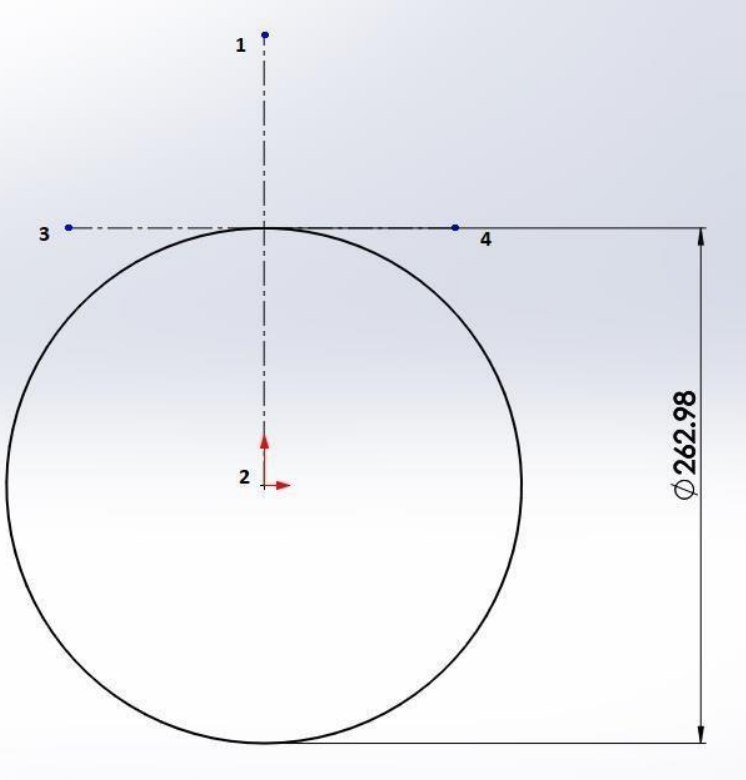

Figure No: 1.2 Tangent to Pitch circle

4. Draw a circle with a seating curve radius at point a.

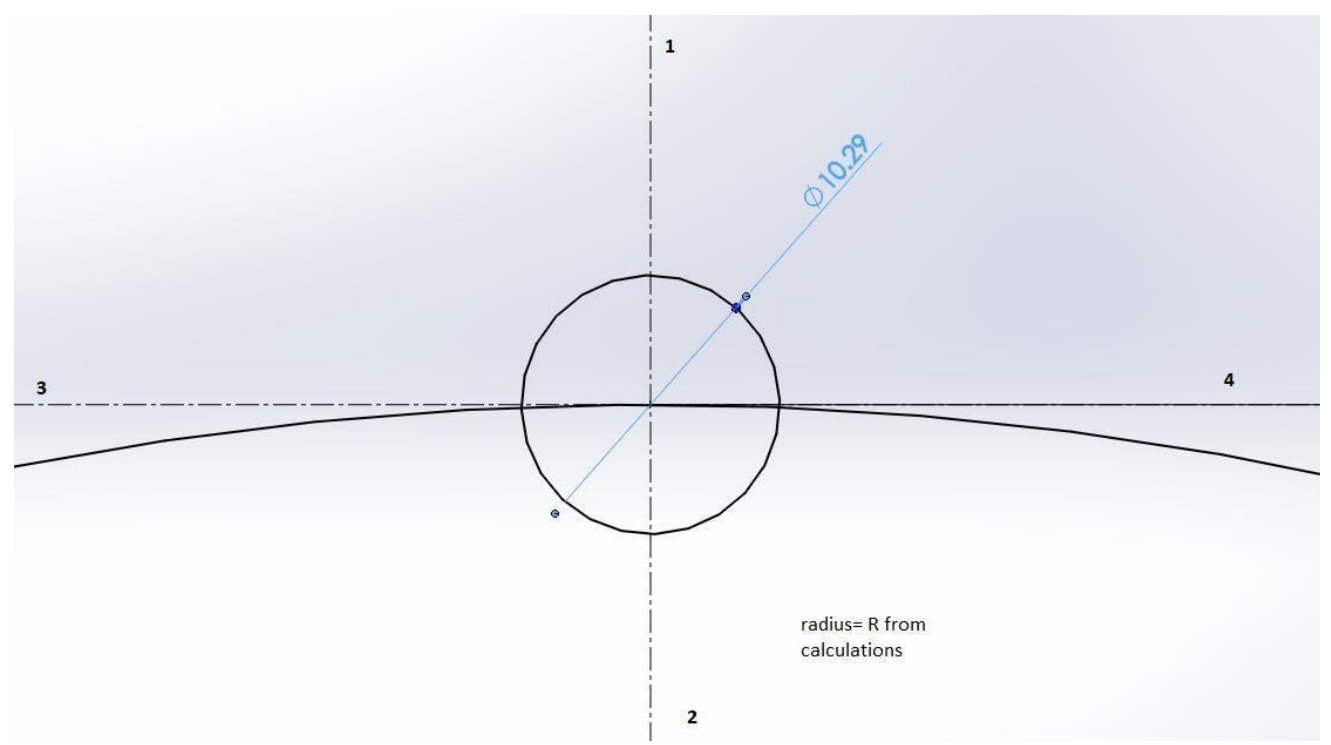

Figure No 1.3 Seating Curve

5. Now offset the lines $(1,2)$ and $(3,4)$ to a distance of $M$ and $T$ respectively. Mark their point of intersection as c. 


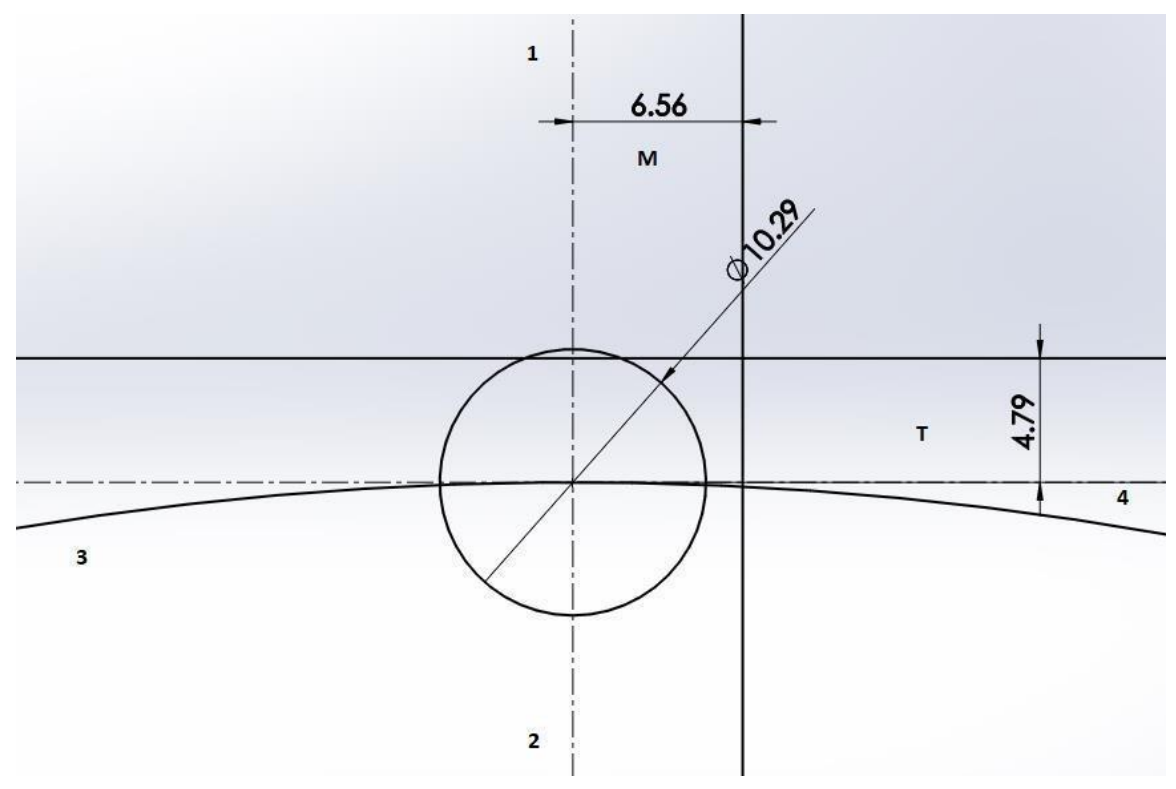

Figure No: 1.4 Offset lines

6. Draw a line cx such that it extends beyond the seating curve circle with an angle A.

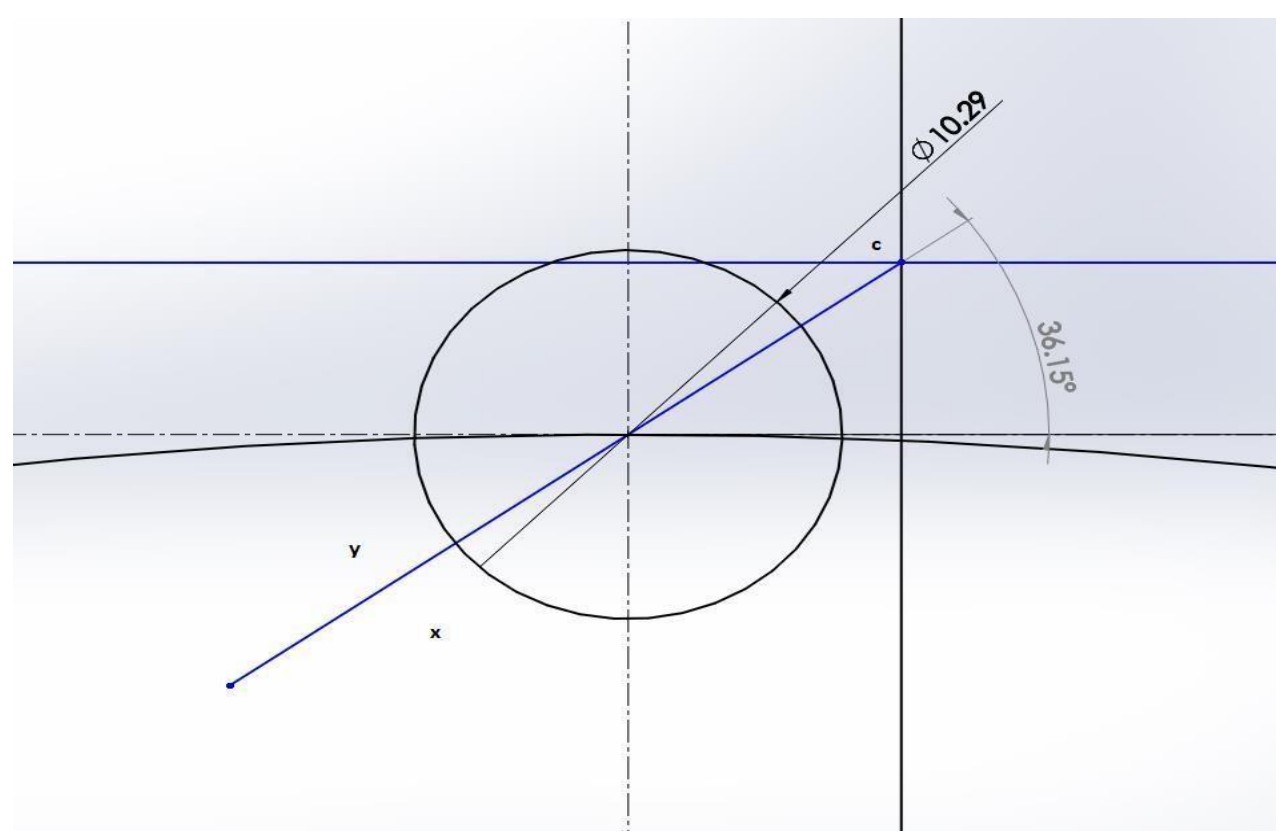

Figure No: 1.5 Seating curve with Angles

7. Draw a line cy $=$ length $\mathrm{E}$ with an angle $\mathrm{B}$ as shown in the figure. By using 3-point arc command draw an $\operatorname{arc}$ from $\mathrm{x}$ to $\mathrm{y}$ with radius equal to length $\mathrm{E}$ taking point $\mathrm{c}$ as center. 




Figure No: 1.6 Arc XY with radius E

8. Draw a line segment yz such that it is perpendicular to the line cy.



Figure No: 1.7 Line YZ (perpendicular to CY)

9. Now offset the lines $(1,2)$ and $(3,4)$ to a distance of $\mathrm{W}$ and V. Mark their point of intersection as point $\mathrm{b}$. 


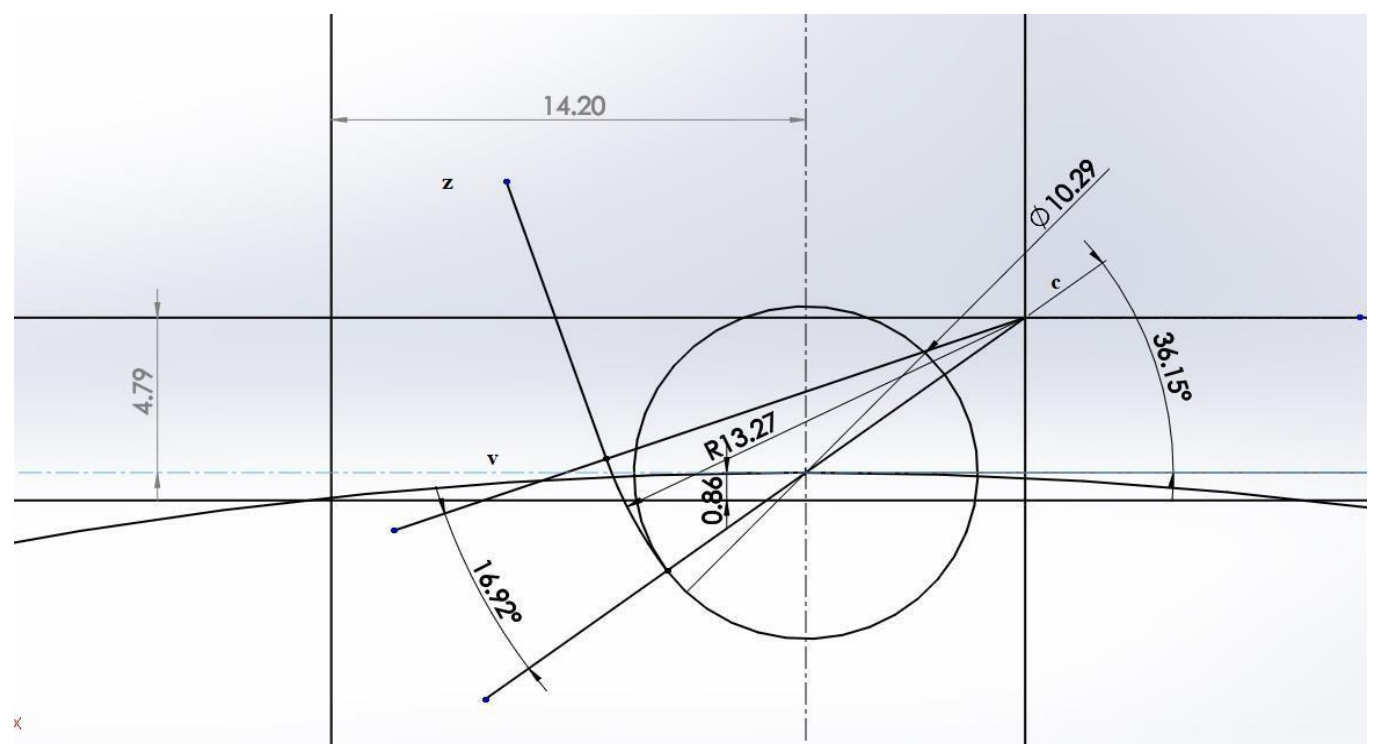

Figure No: 1.8 Offset line $(1,2) \&(3,4)$

10. Draw a circle such that the line yz becomes tangent to that circle.

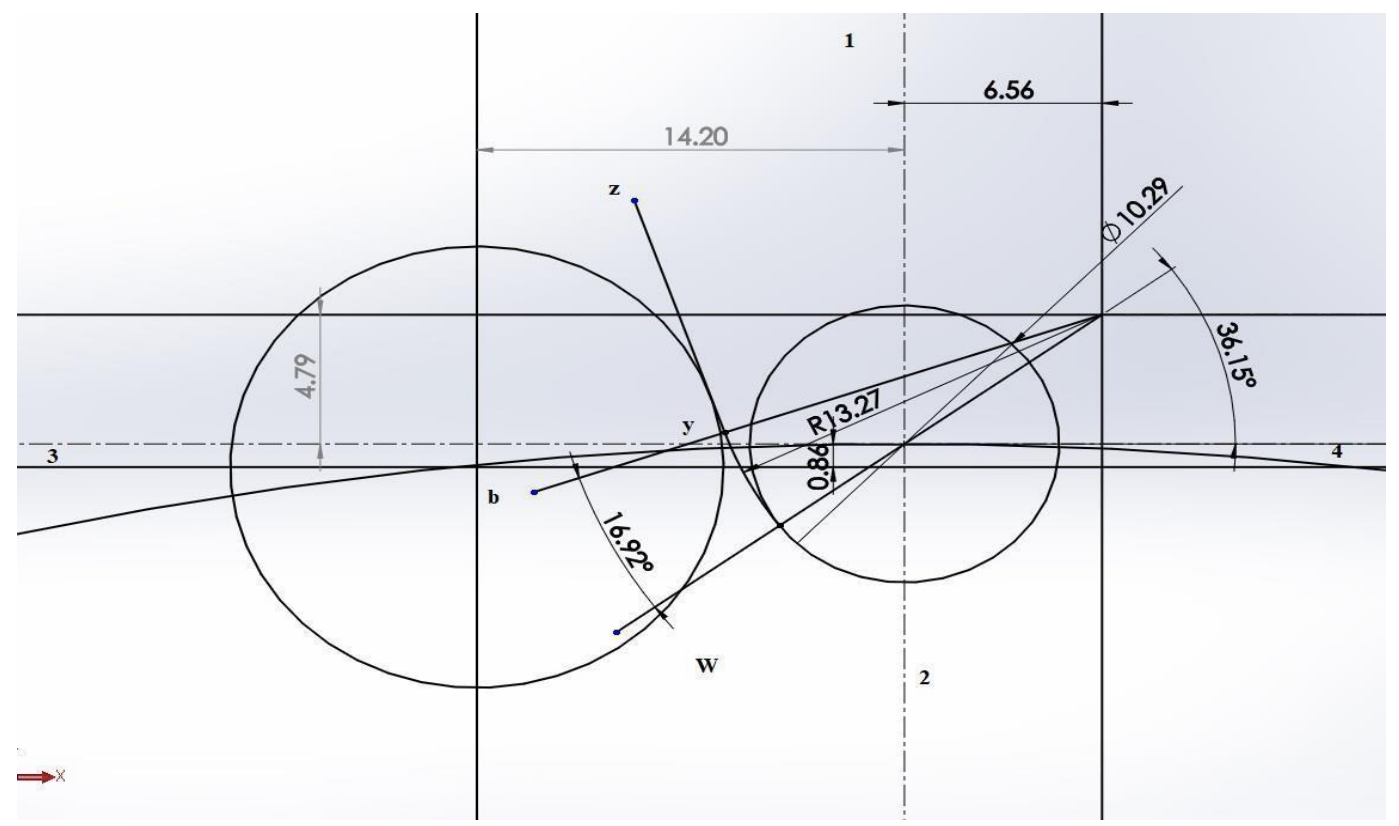


Figure No: 1.9 Circle with YZ tangent

11. In order to locate the tip of the tooth, draw a line from the center of the pitch circle with an angle of $180^{\circ} / \mathrm{N}$ with the vertical.



Figure No: 2.0 Location of tooth tip

12. Except the half tooth profile, pitch circle, and the mirror axis, all the remaining sketch is trimmed off by using the trim command. 




Figure No: 2.1 Trimming the sketch

13. Mirror the tooth profile about the line $(1,2)$. This forms the entire tooth profile.

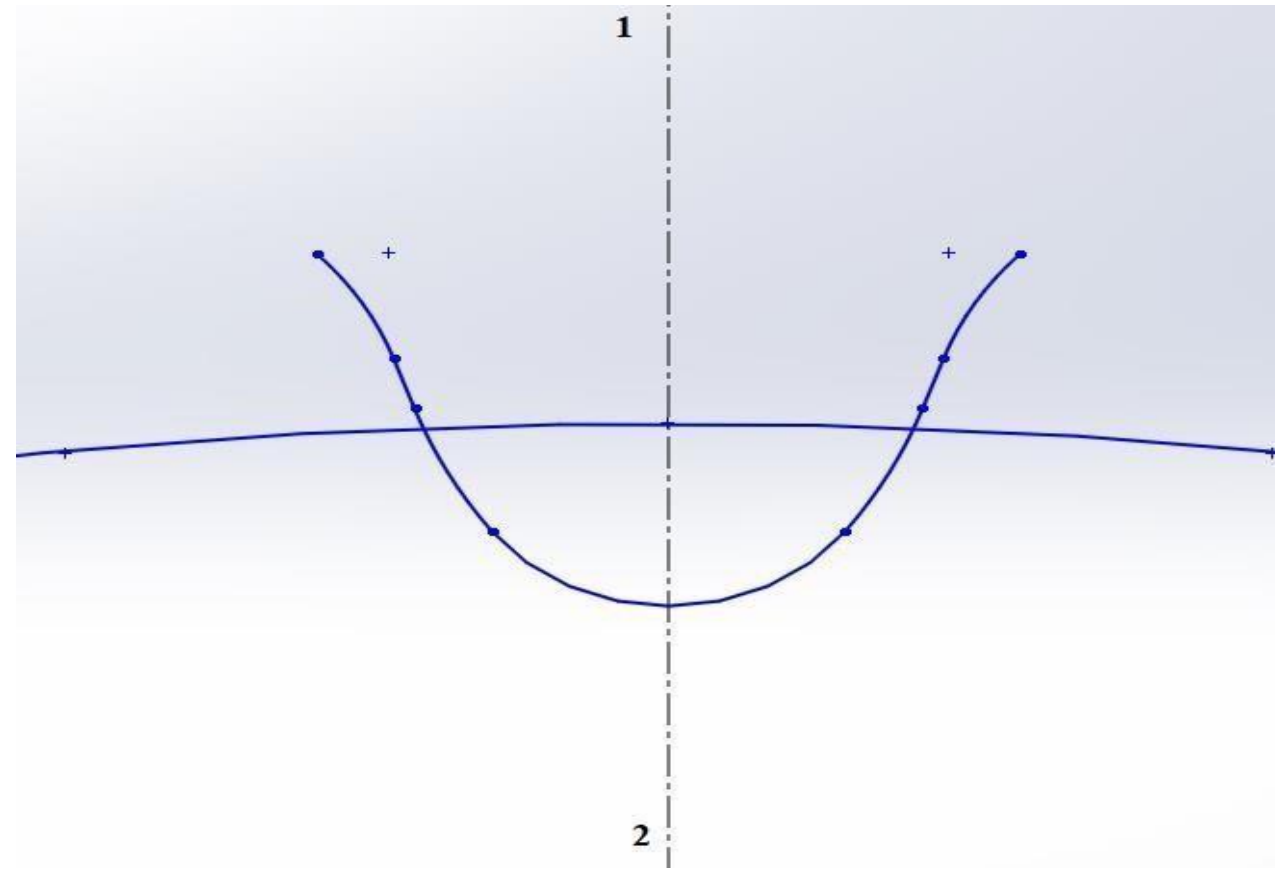

Figure No: 2.2 Mirroring of tooth profile

14. Array the tooth profile about the center of the pitch circle with the help of a circular pattern providing it with 52 instances of tooth profile. 


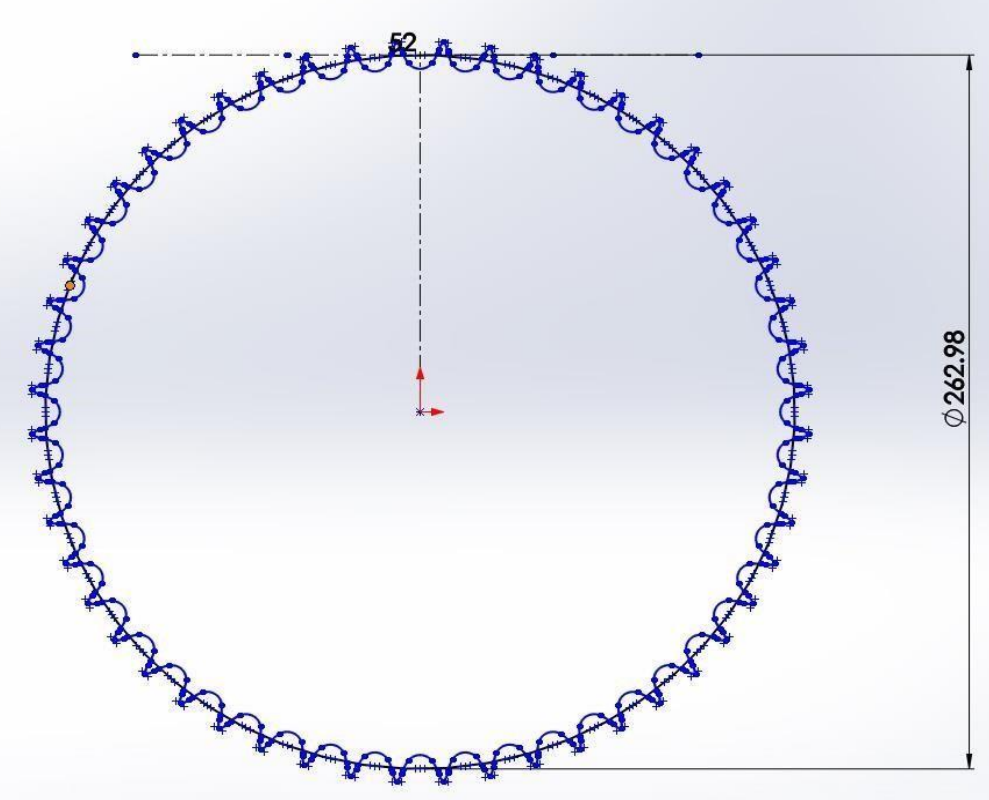

Figure No:2.3 Array of tooth profile

15. Now extrude the sprocket by providing it with the required thickness which is calculated by using the formula, Thickness of sprocket $=0.93 *$ roller width $-0.006 "$ ".

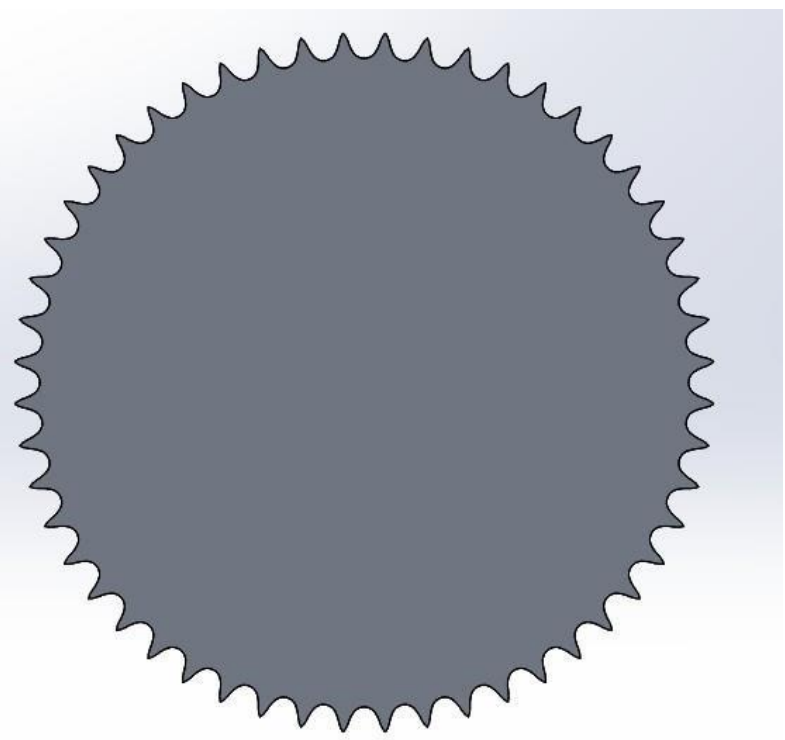

Figure No: 2.4 Sprocket after extruding the sketch 
16. By using the Extrude cut command provide hub holes of diameter $8 \mathrm{~mm}$ with PCD of $110 \mathrm{~mm}$ and shaft hole with a diameter of $35 \mathrm{~mm}$ at the center.

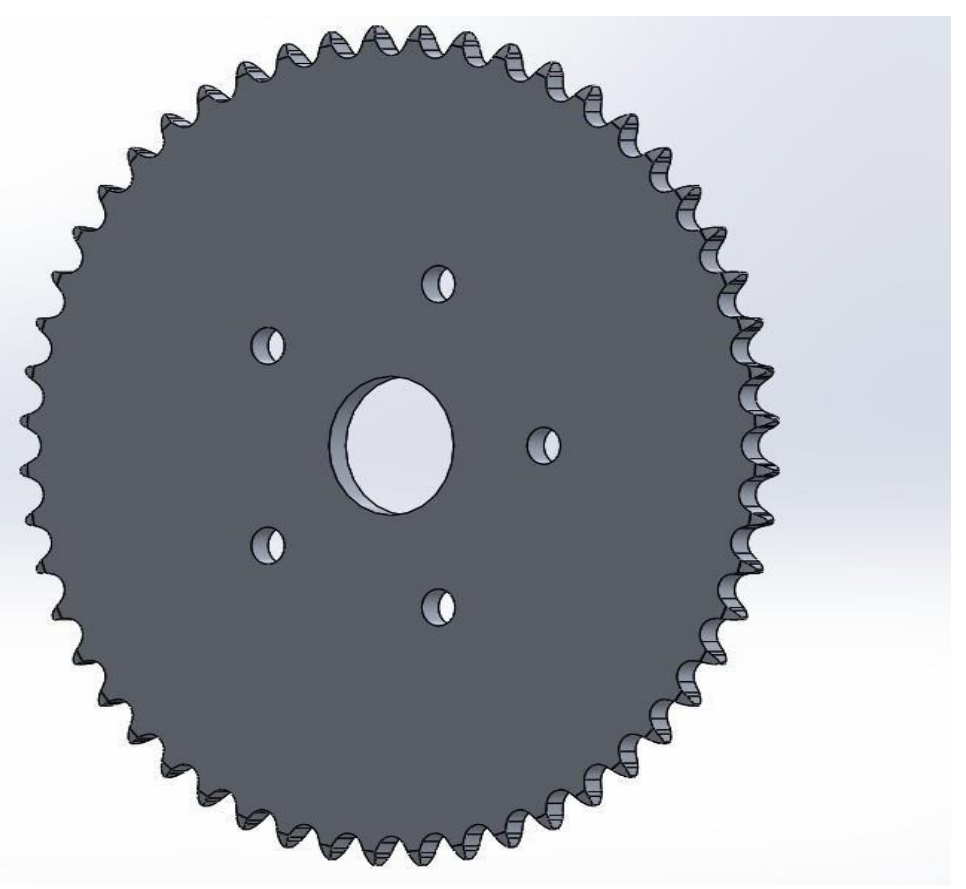

Figure No:2.5 Final Design of sprocket

Thus, the CAD model of the 52 teeth sprocket with a pitch of 0.625 " has been created by following the above design procedure and can be used for analysis. 


\section{ANALYSIS}

A chain drive is a commonly used for transferring power. It mainly consists of chain, drive and driven sprocket. The driver sprocket is connected to the engine output shaft which transfers power to driven sprocket by a chain.

While transferring the power from driver sprocket to driven sprocket, the chain exerts high loads on the sprocket teeth.

The maximum loads acting on the teeth are calculated. Stresses induced due to the load exerted by chain should be less than the yield stress of the material. If not, there is a possibility of failure. Hence static analysis is performed to ensure that the factor of safety is greater than 1 .

Since cyclic loads are acting on the sprocket, the fatigue analysis is to be done to determine the fatigue life of the sprocket.

After minimum fatigue life cracks will be developed in the component and this increases with respect to time which leads to the failure of the component.

FEA is used to perform the static analysis and fatigue analysis of the component. This ensures the safety and reliability of the component.

To perform FEA, ANSYS software is used. Now to perform the analysis in Ansys software, we need to determine the force or load acting on each tooth. This can be determined by the following formula.

$\mathrm{T}_{\mathrm{K}}=\mathrm{T}_{\mathrm{O}} *(\sin \varphi / \sin (\varphi+2 \beta))^{\mathrm{k}-1}$

Where

$\mathrm{T}_{\mathrm{K}}=$ back tension at tooth $\mathrm{k}$

$\mathrm{T}_{\mathrm{O}}=$ chain tension $=3295.044686 \mathrm{~N}$

$\Phi=$ minimum pressure Angle $=17^{\circ}-64^{\circ} / \mathrm{N}=15.7692$

$\mathrm{N}=$ number of teeth on driven sprocket $=52$

$2 \beta=$ sprocket tooth Angle $=360^{\circ} / \mathrm{N}=6.923$

$\mathrm{K}=$ number of engaged teeth $=$ Angle of wrap $* \mathrm{~N} / 360^{\circ}$

$$
=200^{\circ} * 52 / 360^{\circ}=28.88
$$

The general recommendation is to use $1 / 3.5$ of the allowable tension like the back tension. 


\begin{tabular}{|c|c|}
\hline Teeth number & Force on each tooth $(\mathbf{N})$ \\
\hline $\mathrm{T}_{1}$ & 941.4413 \\
\hline $\mathrm{T}_{2}$ & 683.0037 \\
\hline $\mathrm{T}_{3}$ & 495.5105 \\
\hline $\mathrm{T}_{4}$ & 359.4866 \\
\hline $\mathrm{T}_{5}$ & 260.8030 \\
\hline $\mathrm{T}_{6}$ & 189.2093 \\
\hline $\mathrm{T}_{7}$ & 137.2689 \\
\hline $\mathrm{T}_{8}$ & 99.5868 \\
\hline $\mathrm{T}_{9}$ & 72.2490 \\
\hline $\mathrm{T}_{10}$ & 52.4157 \\
\hline $\mathrm{T}_{11}$ & 38.0269 \\
\hline $\mathrm{T}_{12}$ & 27.5880 \\
\hline $\mathrm{T}_{13}$ & 20.0418 \\
\hline $\mathrm{T}_{14}$ & 14.5204 \\
\hline $\mathrm{T}_{15}$ & 10.5344 \\
\hline $\mathrm{T}_{16}$ & 7.6425 \\
\hline $\mathrm{T}_{17}$ & 5.5446 \\
\hline $\mathrm{T}_{18}$ & 4.0225 \\
\hline $\mathrm{T}_{19}$ & 2.9183 \\
\hline $\mathrm{T}_{20}$ & 2.1171 \\
\hline $\mathrm{T}_{21}$ & 1.5359 \\
\hline $\mathrm{T}_{22}$ & 1.1143 \\
\hline $\mathrm{T}_{23}$ & 0.8084 \\
\hline $\mathrm{T}_{24}$ & 0.54864 \\
\hline $\mathrm{T}_{25}$ & 0.4255 \\
\hline
\end{tabular}


Table No-12: Force Calculation Table

From the above calculation, it is found that the maximum tension will at on the first teeth and then it decreases continuously.

\subsection{Material Selection: -}

The strength and weight the sprocket relies on the material used for manufacturing the sprocket. The material selection is an important consideration.

Aluminium alloy is used for making of the sprocket.

Properties of Aluminium alloy 7075-T6

Density $=2810 \mathrm{Kg} / \mathrm{m}^{3}$

Tensile yield strength $=503 \mathrm{MPa}$

Tensile ultimate strength $=572 \mathrm{MPa}$.

Young's modulus $=10.3 * 10^{3} \mathrm{Ksi}$

Fatigue strength $=159 \mathrm{MPa}$

\subsection{Mesh generation for Sprocket Analysis: -}

The CAD model of the sprocket with 52 teeth that have been with designed with standard specification by using Solid Works, is imported into the ANSYS.

After importing the sprocket CAD model, required material is provided to the component and then it undergoes meshing operation. In order to generate mesh, meshing tool is used in which HEX DOMINANT method is specified with a mesh size of $1.5 \mathrm{~mm}$ and refinement is provided in order to generate a fine mesh 


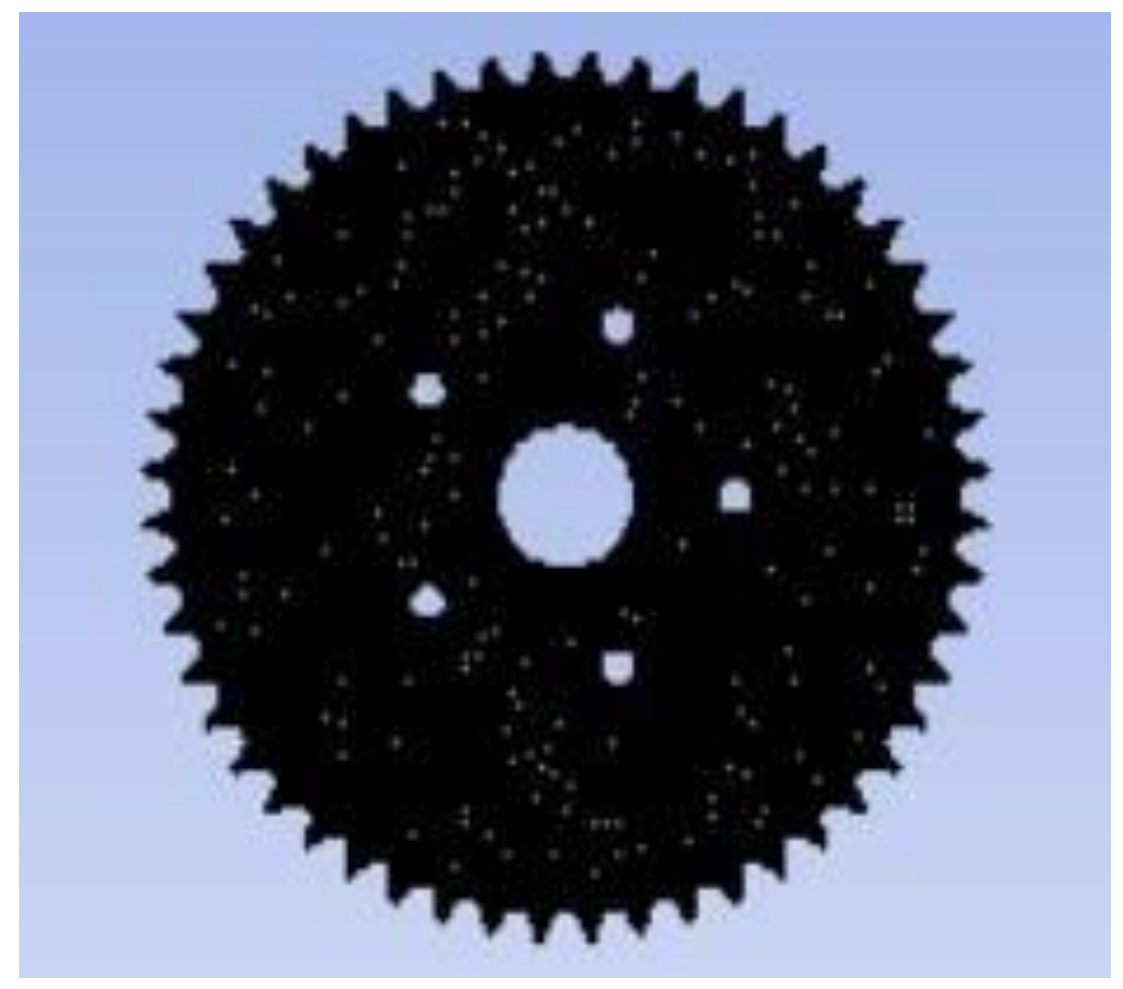

Figure No: 2.6 Meshing

\subsection{Static Structural Analysis: -}

In static analysis, proper specification of the constraints \& loads becomes an important factor. Constraints are specified in such a way that the cylindrical support is provided to shaft hole and remote displacement is provided to either one of the sprocket faces. The forces on each teeth that are calculated above an applied on the teeth flank with direction perpendicular to the sprocket teeth flank.

Now solve the static structural model to understand the stresses developed and total deformation that the model experiences. The below figures are the plots showing Von-mises stress and Total deformation. 


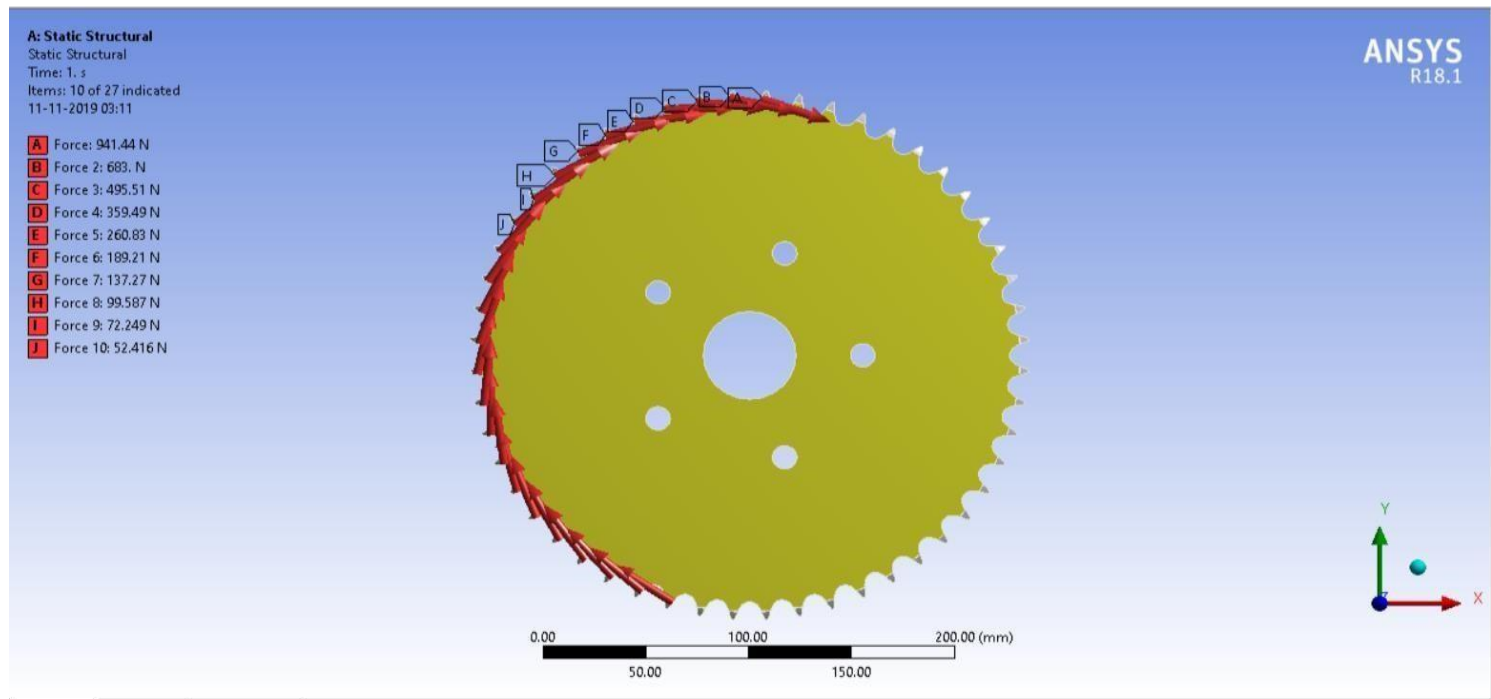

Figure No:2.7 Force on each tooth with direction



ANSYS

Von-mises stress

Figure No:2.8 


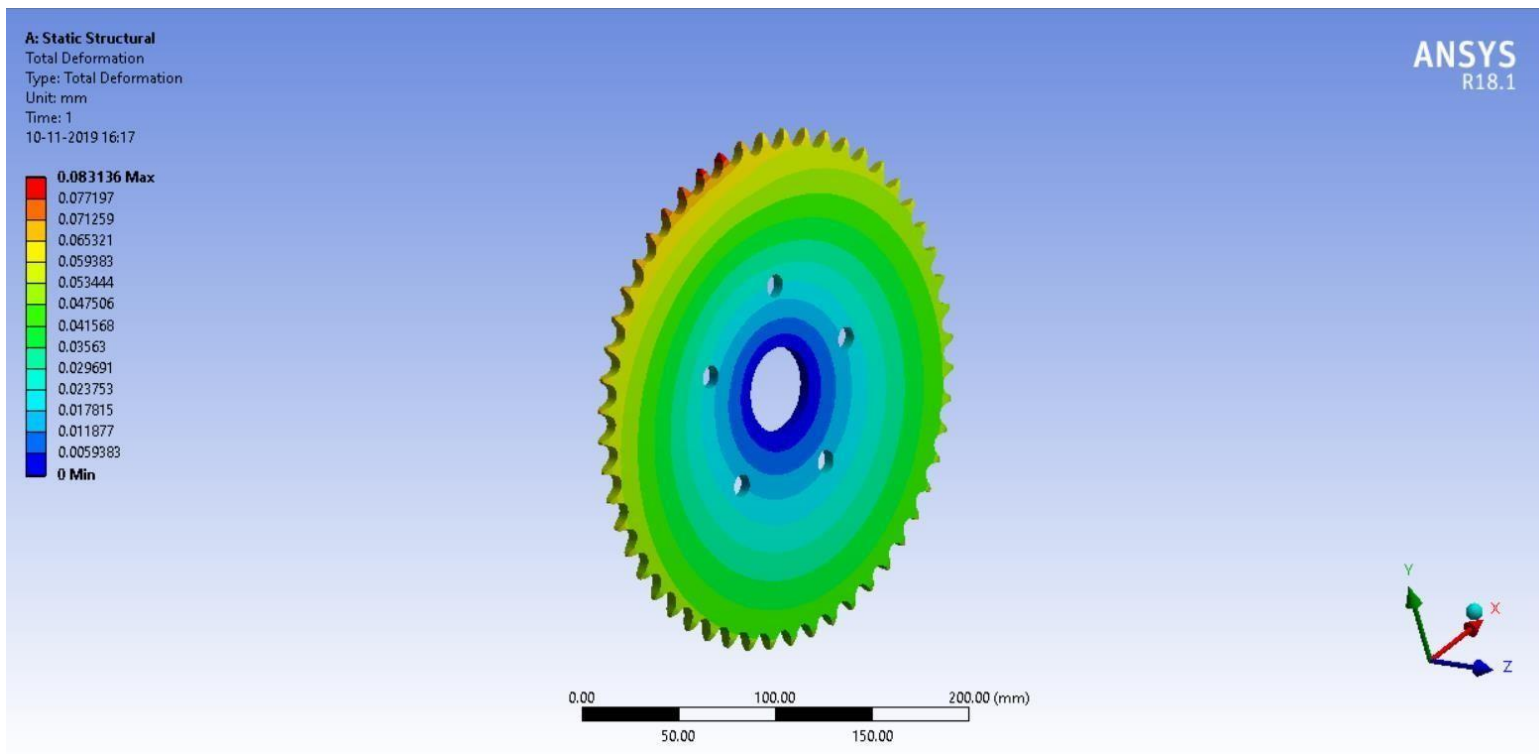

Figure No: 2.9 Total Deformation

According to the Von-mises stress (Equivalent stress) the maximum stress is found to be $69.34 \mathrm{MPa}$ which is less than the yield stress of Aluminum Alloy. Therefore, the factor of safety is greater than 1 . While the maximum deformation obtained is $0.083136 \mathrm{~mm}$ which is negligible. Hence the design is under safe limit.

\subsection{Fatigue Analysis:}

The fatigue life of a member or of a structural detail subjected to repeated cyclic loadings is defined as the number of stress cycles it can withstand before failure. Fatigue analysis on sprocket is done to calculate it's fatigue life by using fatigue tool in ANSYS.



Figure No: 3.0 Fatigue life 




Figure No: 3.1 Damage

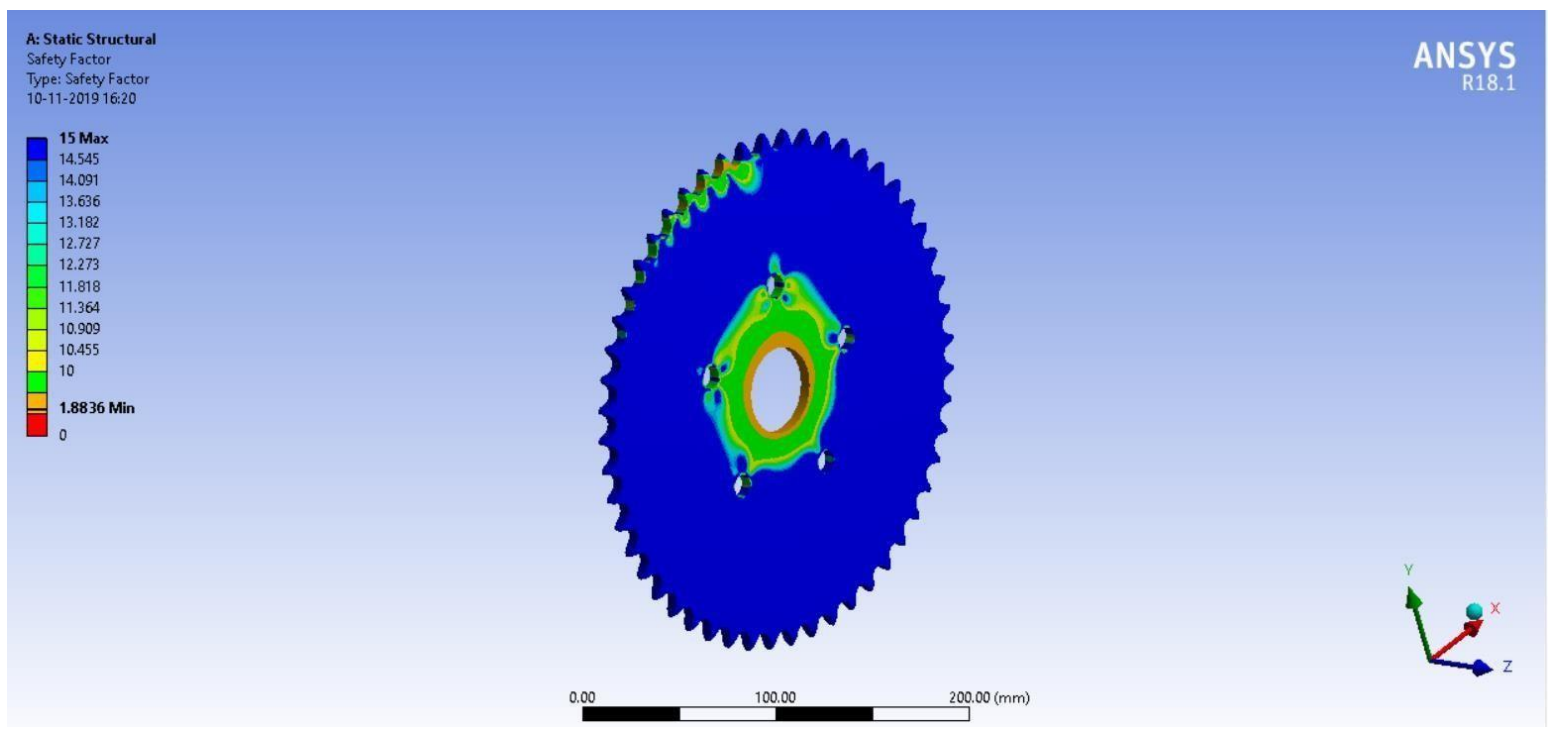

Figure No: 3.2 factor of safety

From the above analysis, it is found that the maximum life and minimum life of the sprocket is $1 * 10^{8}$ cycles \& $5.46 * 10^{7}$ cycles with a factor of safety above 1.8836 .

Hence the design is safe.

In a formula student vehicle, the weight of car is also an important factor and the component used in the vehicle needs to be designed and optimized to achieve less weight in order to increase the vehicle performance. As the sprocket is a rotating component, the rotation- al moment of inertia should be considered which depends on the mass of the component. To achieve good vehicle dynamics the 
rotational moment of inertia should be less. So, the weight reduction should be done. The preliminary design weight is found out to be 855.72 grams

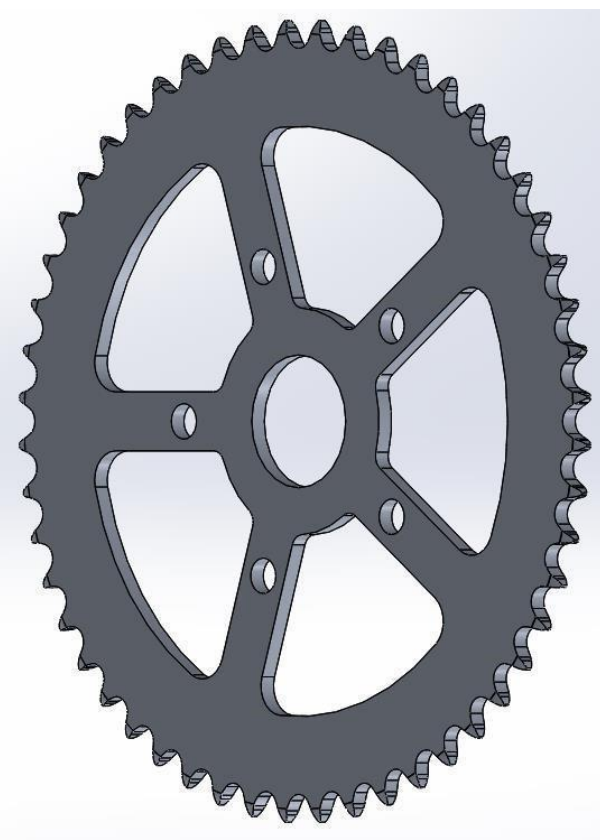

Figure No: 3.3 Modified design of sprocket

The above shown design is the modified design of the sprocket. The modified design of the sprocket weight is 512.05 grams. Thus, modified design of sprocket is to be checked whether it sustains the design loads or not.

\subsection{Static Structural Analysis for modified design:}

Meshing operations, constraints and design load conditions are applied same as the preliminary design and the analysis is carried out. 


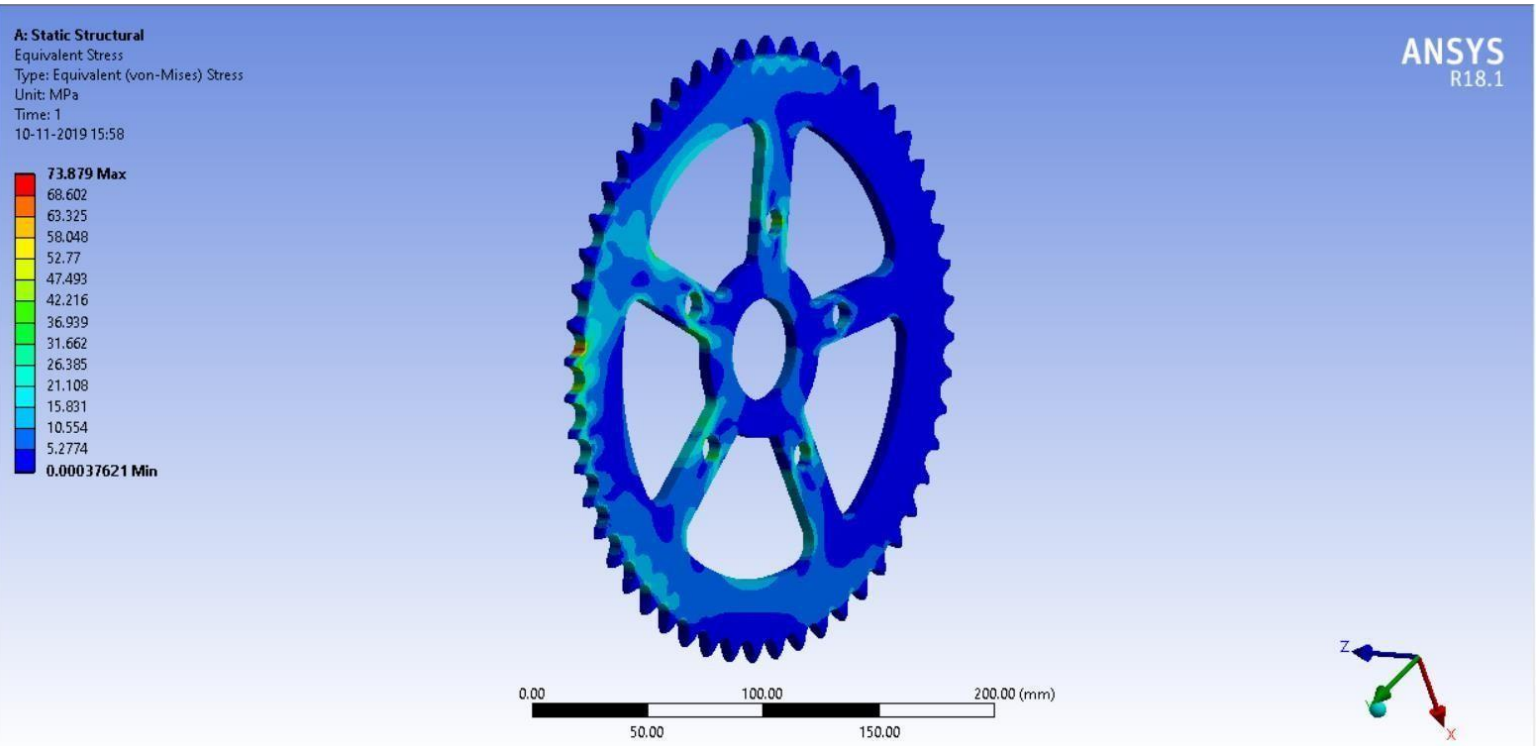

Figure No: 3.4 von-mises stress

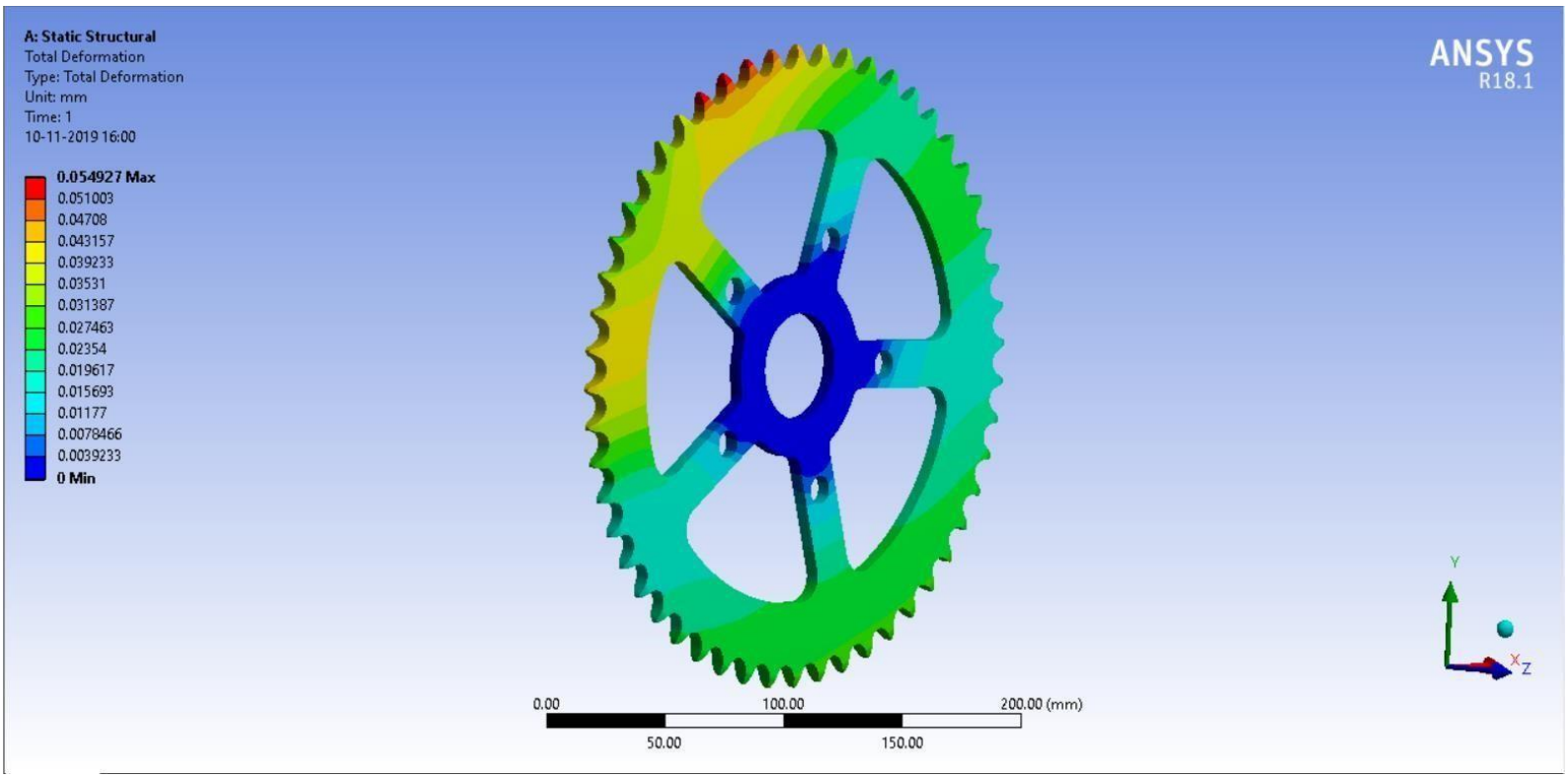

Figure No: 3.5 Total deformation

According to the von-mises stress, the maximum stress is found to be $73.879 \mathrm{MPa}$ which is less than the yield stress of aluminum alloy. Therefore, factor of safety is greater than 1 . While the maximum deformation obtained is $0.05492 \mathrm{~mm}$ which is negligible. Hence the design is under safe limit.

\subsection{Fatigue Analysis for modified design:}

Fatigue analysis has been performed on the modified design with constraints and loads similar to preliminary design analysis. 

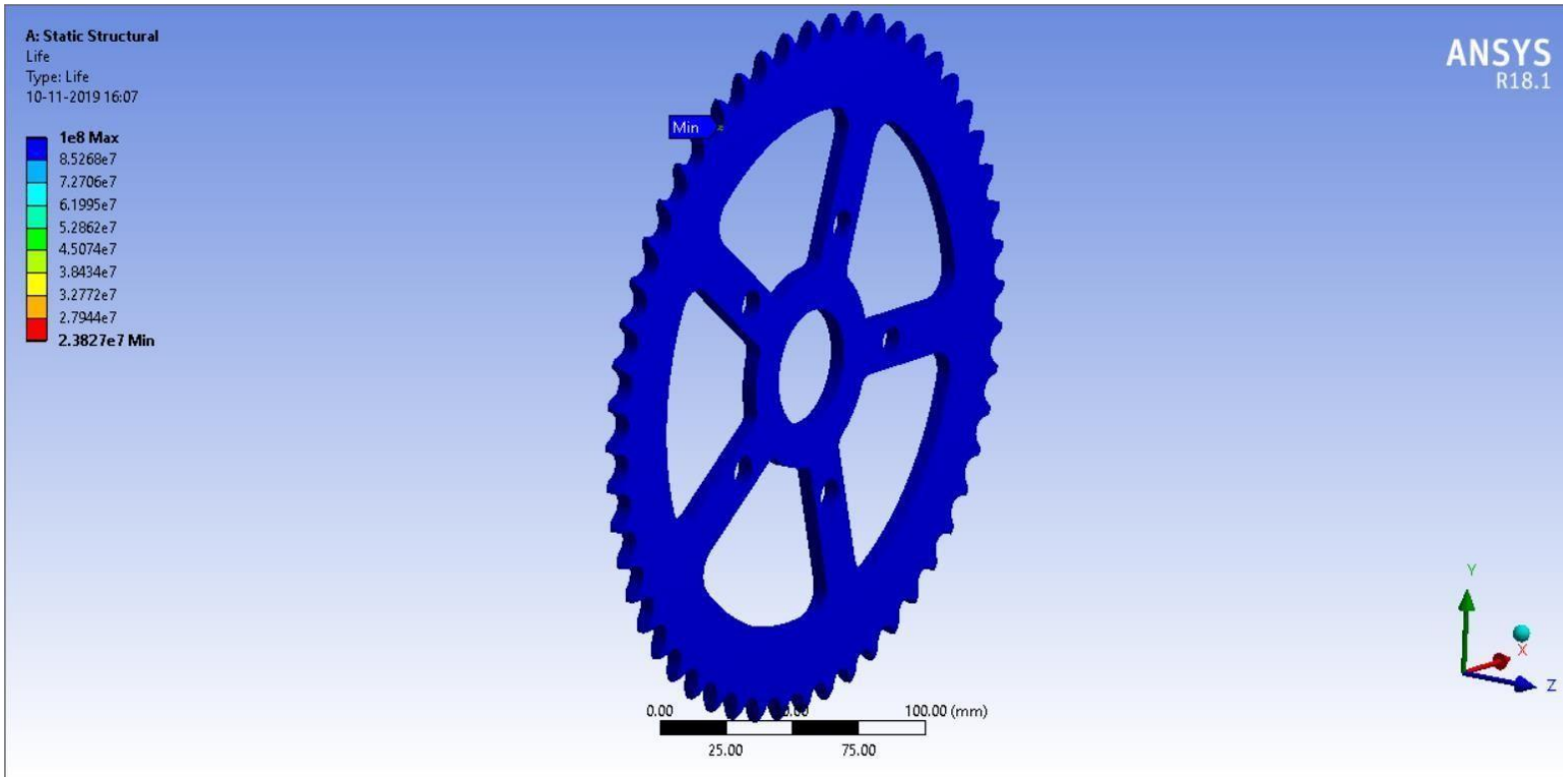

3.6 Fatigue life of modified design

Figure No:

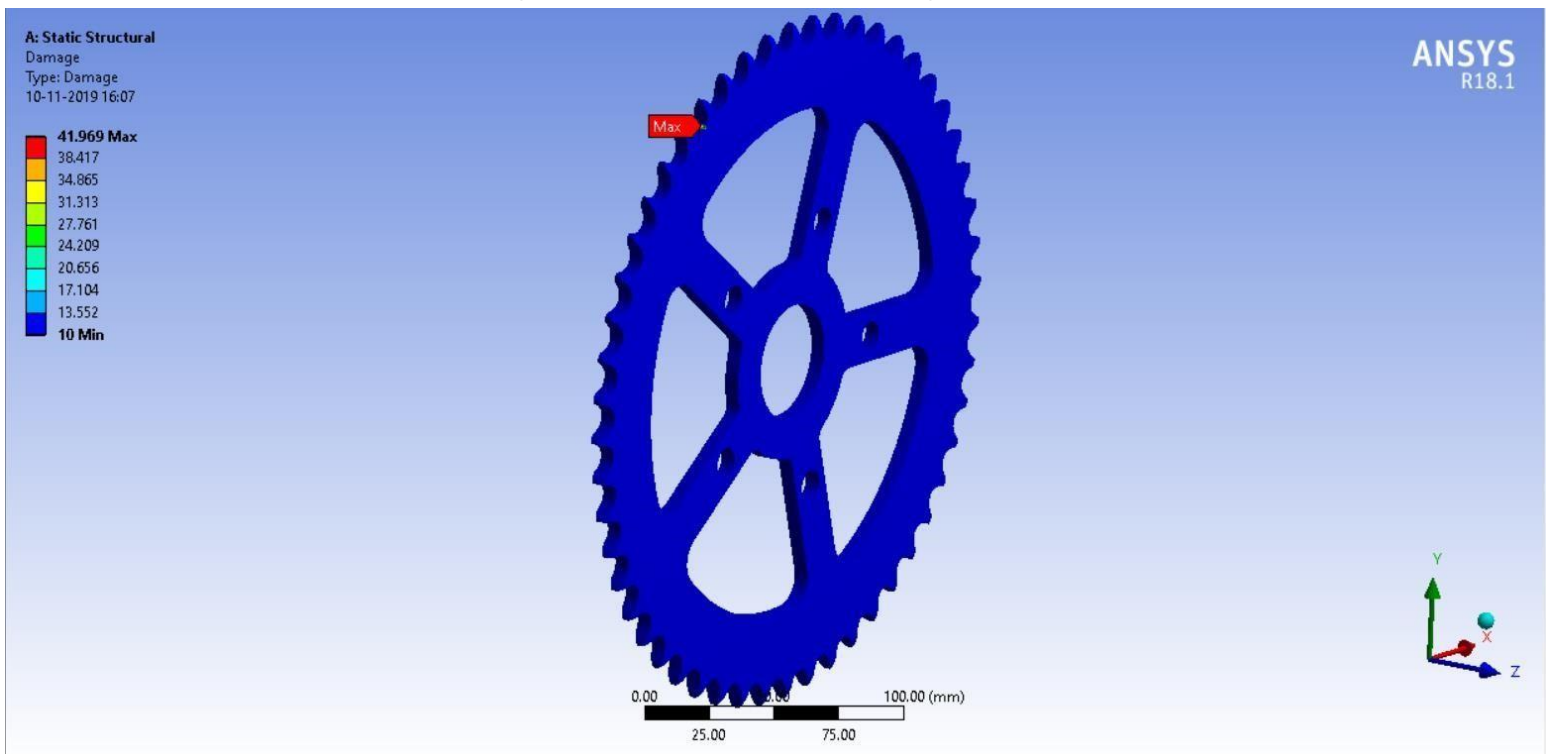

Figure No: 3.7 Damage in modified design 


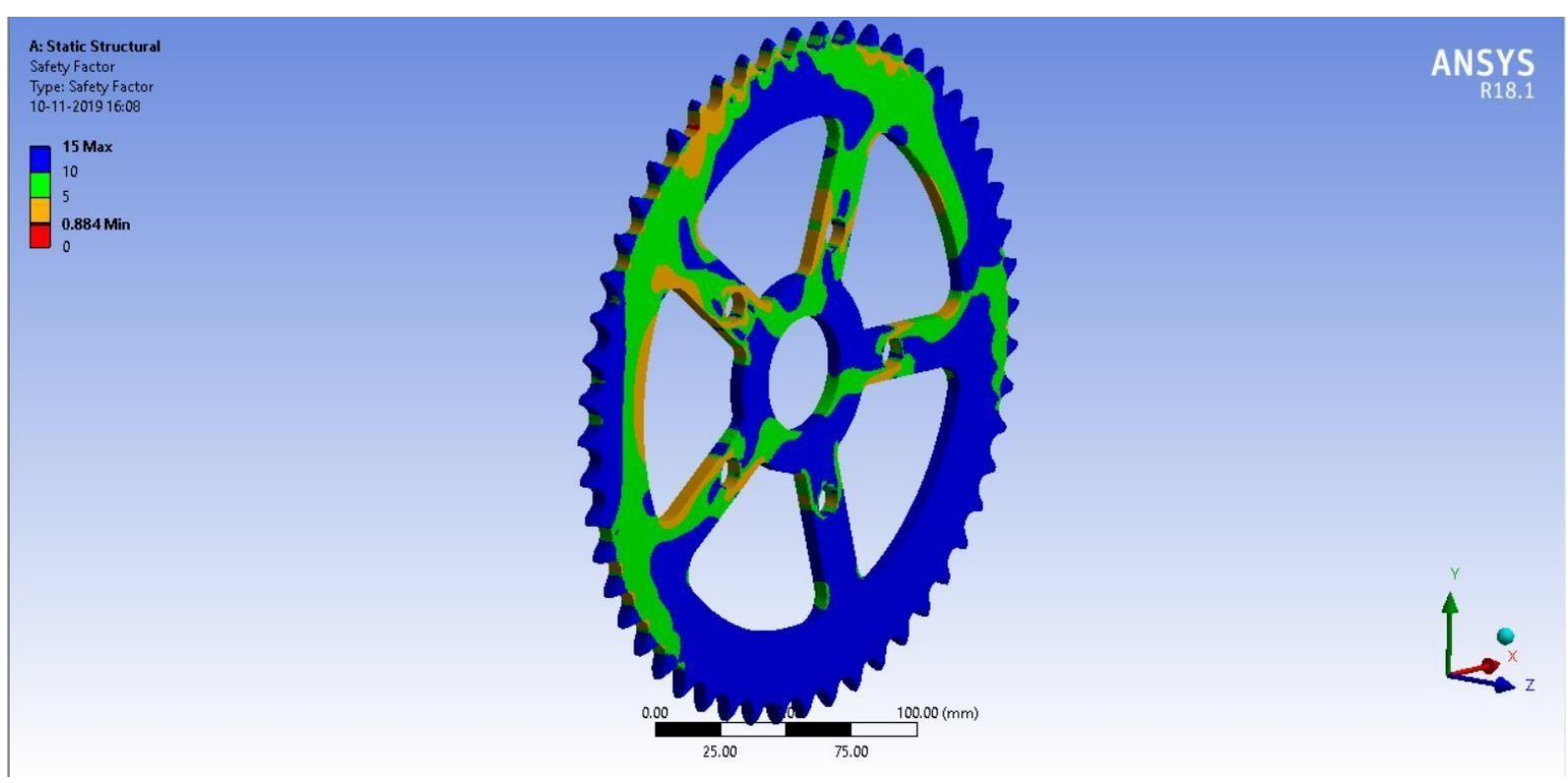

Figure No: 3.8 factor of safety of modified design

From the above analysis, it is found that the maximum life and minimum life of sprocket is $1 * 10^{8}$ cycles and $2.3827 * 10^{7}$ cycles with a factor of safety above 1 .

Therefore, the modified design is Safe.

\section{CONCLUSION}

The design of the sprocket has been successfully optimized with weight reduction of $40.12 \%$. The Deformation of the optimized sprocket is slightly lesser than the preliminary design with a slight increase in von-mises stress with a fatigue life greater than $2.3827 * 107$ cycles, which ultimately results in the safety and reliability of the design. To further increase the reliability and safety factor of the sprocket, different materials with higher strength can be used. 


\section{FUTURE SCOPE}

Advances in Polymers have created plastic gear solutions that are superior to metal gears. Designers have understood the benefits and limitations of plastic gearing, because of reduced weight and lower inertia due to lower density of material.

By using laser cutting method we can achieve more precision in sprocket manufacturing, as of now it is so expensive but, it may get to a reasonable price in future.

Analysis of automotive chain sprocket market says, it will hit big revenues in future. 


\section{REFERENCES}

1. https://en.wikipedia.org > wiki > Sprocket

2. https://isccompanies.com > parts-distribution > sprockets

3. https://en.wikipedia.org > wiki > Water_jet_cutter

4. https://www.google.com/url?sa=t\&source=web\&rct=j\&url=http://www.gearseds.com/f iles/design_draw_sprocket_5.pdf\&ved=2ahUKEwjOoMmrp6PkAhWC6Y8KHeGtA_0Q

FjASegQIBRAC\&usg=AOvVaw1BQ3SacgssuEO3iMf3Smgd

5.https://www.google.com/url?sa=t\&source=web\&rct=j\&url=http://www.ijera.com/paper s/Vol6_issue9/Part-

6. Design Machine Member Text Book.

7. Design Machine Member Data Book.

8.https://s.docworkspace.com/d/AGNxMfaEre0k4fiCgZOdFA 9.

http://www.ijera.com 